\title{
Capítulo IV \\ La ciberguerra y sus cuatro teatros operacionales
}

\section{La ciberguerra desde una perspectiva teórico-conceptual}

\begin{abstract}
A partir de la posguerra fría, se plantea una nueva tipología de ba- talla que se caracteriza por el empleo de las computadoras y la comunicación en red (que integra a las terminales al sistema mundial) para atacar a un enemigo mediante el empleo de información con fines psicológicos y de desarticulación logística, o por hacer uso de las tecnologías de la información para la organización estratégica, operacional y logística de los diversos componentes y recursos de las fuerzas militares a nivel global (Henry y Peartree, 1998).

Esta nueva forma de enfrentamiento solo requiere una computadora conectada a internet y un objetivo. En ese sentido, se aleja de la concepción moderna de la guerra tradicional. En la ciberguerra no es fundamental ni el tiempo, ni el espacio, ni el clima, ni el arsenal, ni el número de tropas, ni la movilización, ni las pérdidas de vidas humanas (Sampaio, 2001). Se requiere, como conclusión de los capítulos precedentes, el ciberespacio como dimensión para la ciberguerra, infraestructuras críticas como objetivos militares, computadoras y redes informáticas para crear y lanzar armas informáticas y cibernéticas, y
\end{abstract}


cibersoldados para que lleven a cabo las operaciones y tácticas que demanda la ciberguerra. El factor central de la ciberguerra radica en encontrar brechas de seguridad para afectar las redes y los dispositivos informáticos de otros Estados. Los ataques cibernéticos capitalizan las debilidades que tiene el sistema informático para extraer información estratégica o boicotear procesos vitales para la nación.

El uso masivo de las tecnologías informáticas y de las redes de comunicación ha cambiado la forma en que operan los Estados. Por esto, los gobiernos, mediante una compleja red de computadoras, administran los sistemas de tránsito vehicular y aéreo, los sistemas de defensa militar y, en general, toda la infraestructura crítica de la nación (Geers, 2009).

Si bien a estas alturas es claro que se hace un estudio del conflicto en el ciberespacio, es importante estudiar el nacimiento del prefijo ciber, raíz de la palabra cibernética. Desarrollada en la próspera era de investigación que siguió a la Segunda Guerra Mundial, la cibernética fue definida como el estudio teórico de los procesos de comunicación y de control en sistemas biológicos, mecánicos y artificiales. Su nombre proviene de la voz griega kybernetes, traducida como timonel o gobierno, con lo que la comunicación es asociada con las nociones de control, regulación y dominio (Siles, 2007, p. 88).

La cibernética fue definida como la ciencia del control y la comunicación entre el animal y la máquina, en una palabra, como el arte de la dirección (Velandia, 2006). Consiste en considerar las estructura y el funcionamiento de los seres vivos como sistemas complejos, basándose en los conceptos de la teoría de la información y las neurociencias computacionales. Considera también cómo se llevan a cabo los procesos de comunicación, los mecanismos de control y los conceptos de retroalimentación en los seres vivos y en las máquinas (Jiménez, 2008, p. 53).

La cibernética es la ciencia que estudia los principios abstractos de organización en los sistemas complejos. No se trata tanto de en qué consisten los sistemas, sino de cómo funcionan. La cibernética se centra en cómo los sistemas utilizan la información, los modelos y las acciones de control para orientar y mantener sus objetivos, al tiempo que contrarrestan diversas perturbaciones. Siendo 
intrínsecamente transdisciplinario, el razonamiento cibernético puede aplicarse para comprender, modelar y diseñar sistemas de cualquier tipo: físicos, tecnológicos, biológicos, ecológicos, psicológicos, sociales o cualquier combinación de ellos. La cibernética de segundo orden en particular estudia el papel del observador (humano) en la construcción de modelos de sistemas y otros observadores $^{34}$. (Heylighen y Joslyn, 2001, p. 1)

La cibernética estudia los flujos de información que rodean un sistema y la forma en que esta información es usada por este como un valor que le permite controlarse a sí mismo. Entonces, la información es para la teoría cibernética un elemento fundamental para la organización del sistema. El concepto de información utilizado por la cibernética tiene su origen en la teoría comunicativa de Shannon y Weaver, que trataba de la transmisión de mensajes, y actualmente está integrada en la teoría de la comunicación. Esta noción de información está basada en la medida de la información a través de unidades elementales de información o bits, muy utilizados en la actualidad en la informática y las telecomunicaciones. A esta dimensión de la información, la cibernética le añade un sentido organizacional. De hecho, un "programa" portador de información lo que hace es comunicar un mensaje a una máquina que computa un cierto número de operaciones (Gros, 2001).

Cualquier ser, biológico, artificial o mecánico, puede ser definido respecto del tipo de intercambios de información que sostenga con su entorno: todos son entes basados en la información. Ante esto, surge la cibernética, con el fin de entender estos comportamientos de intercambio, expresión que terminó entendiéndose como comunicación, concebida como un comportamiento de información, en perpetua reacción con su ambiente (Siles, 2007, p. 89). Wiener afirma que,

al dar la definición de cibernética en la primera edición, puse en la misma categoría las comunicaciones y el gobierno de las máquinas. ¿Por qué lo hice? Cuando me pongo en contacto con otra persona, le doy un mensaje; cuando responde, me da algo en relación con

34 Traducción del autor. 
lo que dije que contiene informes accesibles a él primordialmente y no a mí. Cuando regulo los actos de otra persona, le comunico un mensaje; aunque esté en modo imperativo, la técnica de la comunicación no difiere de la del que enuncia hechos. Además, si mi regulación ha de ser efectiva, debo tomar conocimiento de cualquier mensaje de él que indique haber comprendido y obedecido la orden. (citado por Castro y Filippi, 2010, p. 160)

Durante la Segunda Guerra Mundial, a Wiener se le encomendó la creación de mecanismos de control para la artillería antiaérea que tuvieran la capacidad de regular su propia trayectoria. Este diseño le condujo al estudio del proceso de regulación de los organismos vivos y lo que Wiener hizo fue extraer los datos que sobre biología se poseían y aplicarlos al diseño de la máquina. Es este un dato muy relevante, pues la comparación funcional entre la mente y la máquina que posteriormente incorporó la psicología cognitiva y la inteligencia artificial encuentran aquí sus orígenes. Pero también es importante porque hasta aquel momento no había habido ninguna relación entre los estudios biológicos y el diseño de máquinas, aspecto presente en la actualidad tanto en el diseño del hardware como del software (Gros, 2001).

Mientras que las perturbaciones resistidas en una relación de control pueden originarse dentro o fuera del sistema, funcionalmente podemos tratarlo como si todo él proviniera de la misma fuente externa. Para lograr su objetivo, a pesar de tales perturbaciones, el sistema debe tener una forma de controlar su efecto sobre sus variables esenciales ${ }^{35}$. (Heylighen y Joslyn, 2001, p. 13-14)

Los componentes estructurales de la teoría de control son las tareas, el esquema de actividad, las condiciones, los tipos, los sujetos, los métodos, las formas, los medios, las funciones, los factores que influyen en la eficacia, los principios y los mecanismos de control (Novikov, 2016, p. 35). El control que se ejerce a través de la cibernética tiene ciertos principios esenciales: jerarquía, unificación, decisión, franqueza, eficiencia, responsabilidad, no interferencia, participación y control

35 Traducción del autor. 
social y estatal, desarrollo, adaptación, coordinación, ética y descentralización, entre otros (p. 45).

La palabra cibernética se utiliza, en primer lugar, asociada al uso de la tecnología informática y, posteriormente, al uso de las redes de comunicación. Esta masividad, sumada a una ausencia de alfabetización tecnológica, ha desatado una degeneración del término. Sin embargo, en este uso más masivo, el propio término se ve mutilado (Gros, 2009, p. 2).

En los últimos quince años, una tendencia moderna en la teoría del control ha buscado dirigirse hacia la "miniaturización", "descentralización" e "intelectualización" en sistemas con muchos agentes autónomos interactivos de naturaleza social, técnica o informacional. Las propiedades inherentes de los sistemas multiagentes (multi-agent systems [MAs]) como la interacción descentralizada y la multiplicidad inducen, fundamentalmente, a nuevas propiedades emergentes (autonomía, menor vulnerabilidad a factores desfavorables, etc.) cruciales en varias aplicaciones.

Los MAS se pueden dividir en hardware (publicaciones pioneras que se remontan a mediados de la década de 1990) y software (desde mediados de la década de 1970). Los primeros incluyen robots móviles (robots con ruedas, vehículos aéreos no tripulados, submarinos autónomos no tripulados, etc.) y sistemas de control de complejos objetos industriales y tecnológicos (sistemas de control asistido por ordenador de procesos industriales). Los últimos incluyen sistemas de control en los que los agentes son softbots, es decir, módulos programados autónomos que resuelven problemas de optimización distribuidos según protocolos establecidos (posibles aplicaciones de sistemas logísticos en fabricación y transporte, softbots en redes digitales, esto es, programación en tiempo real, asignación de funciones y tareas, y así sucesivamente) (Novikov, 2016, p. 70).

Realizar una arqueología del prefijo ciber, teniendo en cuenta su popularidad, es explorar un mundo de teorías y presencias, que ha permitido comprender y problematizar los debates en la concepción misma de la tecnología, la cultura, el tiempo y el espacio, como construcción de realidades y subjetividades. Su uso advierte la emergencia de una cultura ligada a los desarrollos de la cibernética, las nuevas 
comprensiones de la biología, la tecnología, la sociología y los usos culturales de la tecnología en la sociedad del conocimiento, pero plantea grandes retos relacionados con la investigación y la construcción de conocimiento transdisciplinar (Téllez, 2016, p. 145).

Si se tiene en cuenta lo anterior, y volviendo al enfoque de la guerra, la ciberguerra se puede definir como "la lucha entre dos Estados o facciones que tiene lugar en el espacio cibernético" (Ortega, 2012, p. 47). También se afirma que es "un ataque digital masivamente coordinado hacia un gobierno por otro, o por grandes grupos de ciudadanos. Es la acción de un Estado nación de penetrar en las computadoras y redes de otra nación con el propósito de causar daño o interrupción" ${ }^{36}$ (Schreier, 2015, p. 16). Se puede entender como la guerra basada en ciertos usos de las tecnologías de la información y de la comunicación (TIC) dentro de una estrategia militar ofensiva o defensiva respaldada por un Estado que apunta a la interrupción o el control inmediato de los recursos del enemigo que se libra dentro del entorno informativo, sobre los dominios físicos y no físicos, cuyo nivel de violencia puede variar según las circunstancias (Taddeo, 2012b, p. 114).

La guerra cibernética tiene algunas diferencias claras con la guerra tradicional, pues no es necesariamente un fenómeno de violencia y destrucción extrema; es decir, "puede involucrar a un virus informático capaz de interrumpir o negar el acceso a la base de datos del enemigo $\mathrm{y}$, al hacerlo, causar un daño grave al enemigo sin ejercer fuerza física ni violencia" 37 (Taddeo, 2012a, p. 211). De igual forma, puede no implicar a los seres humanos, lo cual se refiere a que, si bien el hombre puede llevar a cabo la orden, se puede dirigir a través de agentes artificiales, bases de datos o sitios web. Lo anterior no implica que la ciberguerra no deba ser temida tanto como la guerra convencional. Este fenómeno tiene una característica que es casi imposible de identificar en los demás escenarios; para Taddeo, es transversal, puede llegar a escalar de formas no violentas a formas muy violentas.

36 Traducción del autor.

37 Traducción del autor. 
Durante la guerra del Golfo Pérsico, las fuerzas militares estadounidenses vieron potenciado el desarrollo de sus operaciones y tácticas en el teatro de guerra y operaciones al incluir en su funcionamiento una colosal estructura de tecnologías informáticas, para llevar a un nuevo nivel el comando, el control y las comunicaciones, así como el envío de datos estratégicos al terreno, el desarrollo de operaciones psicológicas, el empleo de armamento inteligente y sofisticadas aeronaves imperceptibles para el enemigo. En síntesis, la información fue una materia prima para llegar a la victoria de manera menos compleja y sorteando muchas dificultades que ocurrían en escenarios precedentes de conflagración (Wilson, 2007).

En la ciberguerra, la información ya no es simplemente una plataforma para llevar a cabo las acciones de guerra de manera más eficiente y eficaz sobre el terreno. La información se ha convertido en el medio y el fin para hacer las acciones de guerra sin ni siquiera estar en el campo de batalla (Dunn, 2010). Bajo esta doctrina, la información se considera como "la artillería" que viaja a través del ciberespacio hacia su objetivo, que es disparada o desplegada por el armamento cibernético, es decir, las computadoras, y los expertos en su uso (Wander, 2003).

Retomando que, según la lógica del ciberespacio, la infraestructura crítica del Estado, la estructura gubernamental y los sistemas de seguridad y defensa se han integrado a esta dimensión como producto de su sinergia con las tecnologías informáticas, la ciberguerra busca el control de estas instancias. Y como en esta dimensión virtual las variables tiempo y espacio se han reconfigurado, los pilares del Estado nación están al alcance del enemigo tanto como este lo esté de una computadora (Bhattacharjee, 2009).

Si consecutivamente al establecimiento conceptual de la blitzkrieg, o guerra relámpago, se prosiguiera con una nueva categoría para entender lo que la ciberguerra representa, sería ahora pertinente entrar a operar con el concepto de la leitenkrieg, o guerra de control (Arquilla y Ronfeldt, 1993).

Con la ciberguerra, se busca que las hidroeléctricas abran sus compuertas sin aviso para inundar poblaciones aledañas, que reactores nucleares se recalienten y entren en crisis (o que dejen de funcionar), que oleoductos y refinerías ardan en llamas, que los sistemas bancarios y 
financieros nacionales sufran desplomes informáticos (que después se reflejan en desplomes reales de la economía), que los controladores aéreos no puedan guiar el tráfico aéreo o que el Gobierno quede incapacitado para prestar servicios y generar vínculos de comunicación de manera efectiva con los ciudadanos (Verising, 2009).

$\mathrm{Al}$ afirmar que la ciberguerra se traduce en una guerra de control, la guerra cibernética se puede explicar como una agresión promovida por un Estado y dirigida a dañar gravemente las capacidades de otro para tratar de imponerle la aceptación de un objetivo propio o, simplemente, para sustraerle información, cortar o destruir sus sistemas de comunicación, alterar sus bases de datos, es decir, lo que habitualmente se ha entendido como guerra, pero con la diferencia de que el medio empleado no sería la violencia física, sino un ataque informático que le permita obtener una ventaja sobre el enemigo para situarse en superioridad o, incluso, derrocarlo (Wilson, 2007).

Según Shea, se logra precisar el concepto donde se une la guerra en el ciberespacio y la infraestructura vital de los actores. La infraestructura crítica se define como los sistemas y los activos, físicos o virtuales, que son sumamente vitales para los Estados, que, en caso de ser incapacitados o destruidos, los activos tendrían un impacto debilitante en la seguridad, la seguridad económica nacional, la salud o la seguridad pública, o cualquier combinación de estos asuntos (2003, p. 1). El nexo con este escenario de amenaza, en distintos países industrializados, se consolida mediante la inclusión de sistemas informáticos de control industrial para formalizar las operaciones de la infraestructura crítica estatal. Tal es el caso de la implementación del Supervisory Control and Data Acquisition (scADA).

Desde la perspectiva cibernética, SCADA ofrece uno de los objetivos más atractivos para los detractores de la seguridad con miras a alcanzar un evento catastrófico. Con el crecimiento exponencial de las redes de sistemas de información que interconectan el sector productivo, administrativo y de sistemas operativos, la agresión se materializa mediante la intrusión al SCADA a fin de modificar los datos utilizados para la toma de decisiones operativas, los programas que controlan los equipos de industria crítica, o los datos comunicados a los centros de control (Foster et al., 2008). 
Durante la primera década del siglo xxi, han existido alrededor del mundo acontecimientos que pueden nombrarse ciberguerra. Se encuentra presente la operación con nombre código Titan Rain, en la cual, durante 2002, un grupo gubernamental de hackers chinos entrenados en el ciberespionaje lograron descargar aproximadamente entre 10 y 20 terabytes de información sensible (pero no confidencial) del Departamento de Defensa de los Estados Unidos (United States Department of Defense [DoD]) a través del Non-Secure Internet Protocol Router NETwork (NIPRNET) y, específicamente, del U.S. Army Information System Engineering Command, del Naval Ocean Systems Center, y de la Missile Defense Agency (Carr, 2011).

A manera de conclusión, dando crédito a los casos acaecidos en los cuales los Estados nación han efectuado ataques en el marco de la lógica de la ciberguerra, es posible evidenciar el nuevo valor que toma la información. Durante la década de 1990, la informática fue una materia prima para desarrollar la guerra en su respectivo teatro. Ahora, con la cibernética, como arte del control, la información es un arma para causar un efecto esperado en los sistemas informáticos del enemigo.

Por supuesto que esta nueva forma de combate toma importancia cuando las computadoras y las maniobras u operaciones, que por medio de estos se adelantan, se traducen en un ataque directo a los cimientos de un Estado nación considerado como enemigo desde la perspectiva del agresor. No en vano, la ciberguerra, con bajos riesgos para los cibersoldados, puede ser vista por los niveles decisorios de la guerra como una forma de establecer un objetivo, pero sin disparar una sola arma. Un atacante podría pensar en una ciberofensiva que inhabilite la red de energía eléctrica y además destruya algunos de los componentes principales del sistema informático de ella (el sistema queda inservible por semanas), un movimiento poco antiséptico, un camino para tener las tensiones en sus niveles más bajos posibles. Pero, para millones de personas entrar en un escenario de oscuridad y tal vez de frío, imposibilitados para conseguir alimentos, sin acceso al dinero ni posibilidad de intercambio producto del desorden social, podría ser, en muchas formas, lo mismo que haber lanzado una bomba sobre una ciudad (Clarke, 2009). 
Se logró constatar que en el nuevo escenario los ejércitos encontraron una tecnología para ser aplicada en los elementos bélicos, a fin de potenciar los medios y las capacidades de la comunicación. Como se evidenció, mediante el empleo de aeronaves dotadas de todo tipo de dispositivos informáticos, y con los misiles que, al estar integrados con sistemas a base de silicio, se hicieron con la capacidad de la teledirección y precisión en el impacto de blancos (Arquilla y Ronfeldt, 1993).

\section{El teatro psicológico: juego con la información}

Irak, en 1990, se convirtió en un teatro de guerra experimental para las TIC. El despliegue de computadoras integradas a sistemas de comunicación en red sobre el teatro de guerra evidenció que se daba paso a un nuevo tipo de guerra, así como a la forma en que se debían conducir las operaciones y establecer su doctrina. Estas transformaciones, que se enmarcaron teóricamente en el enfoque de la revolución de los asuntos militares, dieron paso a las denominadas information war e information warfare (Glebocki, 2008).

Dentro de este marco, igualmente se detectó la aparición de las denominadas operaciones de información (OI), sustentadas por el empleo de las computadoras y su capacidad de enviar la información por internet y caracterizadas por la utilización de herramientas informáticas que permiten la parálisis, el control o la destrucción de la información y los sistemas del enemigo.

Estas herramientas son reconocidas por tener como objetivo efectos psicológicos en el oponente al desarticular sus canales de comunicación, en los que recae la decisiva toma de decisiones entre el alto Gobierno y el Estado Mayor de las fuerzas militares (verticalmente), y el mando, el control y las unidades desplegadas en los teatros de operaciones (horizontales) (Wilson, 2007).

Al funcionar el mundo bajo un sistema informático global, todo aquello que es considerado como centro de gravedad de un Estado se encuentra bajo amenaza. Por ende, todo actor con un conocimiento en cibernética, y acceso a una computadora, que se encuentre conectado 
a internet, tiene la posibilidad de acceder a las redes neurálgicas de una nación, ya sea con intenciones hostiles, ya sea con el objeto de espiar información gubernamental en todos sus ámbitos (Warden, 1995).

Las campañas de propaganda y desinformación han sido, durante mucho tiempo, elementos básicos de la guerra convencional. En la batalla por los corazones y las mentes, el control de las tecnologías de radiodifusión (televisión, radio) ha sido un objetivo fundamental. En un sentido, nada ha cambiado mucho, pero el panorama se ha vuelto más complicado con la aparición de internet y la World Wide Web, que dan voz a los individuos y grupos más inverosímiles, sus propiedades de comunicación multidireccional dan acceso a audiencias que, bajo las condiciones del monopolio de radiodifusión oligopolísticas, habrían permanecido fuera de su alcance. En la era de la información, el enemigo silencioso puede adquirir fácilmente una voz y amplificar rápidamente su mensaje disidente. Los canales unidireccionales están siendo desplazados por patrones de comunicación, lo que hace que el deseo de controlar y censurar sea casi inútili38. (Cronin y Crawford, 1999, p. 258)

A pesar de las diferencias entre los usos de las TIC en la guerra, existe un aspecto que es común a todas las circunstancias, y es el despliegue de estas con una intención disruptiva inmediata, como el uso de armas (semi) autónomas, alguna infraestructura de información o el despliegue de dispositivos digitales para mejorar el desempeño de las fuerzas en el campo de batalla. Este factor común es el primer paso hacia la definición de este nuevo tipo de guerra. La guerra de información es el uso de las TIC con un propósito ofensivo o defensivo para entrometerse, interrumpir o controlar inmediatamente los recursos del oponente (Taddeo, 2012b, p. 109).

La information warfare (IW) fue lanzada formalmente en diciembre de 1992 con la difusión de la Directiva 3600 del DoD. En septiembre de 1995, el subsecretario de Defensa para el Comando, Control, Comunicaciones e Inteligencia (Assistant Secretary of Defense

38 Traducción del autor. 
(Command, Control, Communications, \& Intelligence) [ASD(C3I)]) publicó la definición oficial no clasificada del DoD de IW: medidas adoptadas para lograr la superioridad de la información al afectar la información adversa, los procesos basados en la información y los sistemas de información, al tiempo que se defiende la propia información, los procesos basados en información y los sistemas de información (Fredericks, 1997, p. 80).

Adams (2001) define la guerra de la información como la secuencia de las acciones emprendidas por todas las partes en un conflicto de destruir, degradar y explotar los sistemas de información de sus adversarios. Y también comprende todas las acciones encaminadas a proteger los sistemas de información contra los intentos hostiles a la destrucción, degradación y explotación. Las acciones de guerra de información tienen lugar en todos los lugares de la evolución del conflicto: la paz, la crisis, la escalada, la guerra, la distensión y los posteriores a los conflictos (Delibasis, 2007, p. 6).

La guerra de información es un tipo de guerra electrónica que tiene como objetivo neutralizar y obtener información o monitorear sistemas y redes de información de computadoras enemigas. Además, la capacidad de este tipo de guerra, en un papel defensivo, debe proporcionar una protección adecuada a los sistemas y las redes propios. El DoD Dictionary of Military and Associated Terms la define como las operaciones de información llevadas a cabo durante tiempos de crisis o conflicto para lograr o promover objetivos específicos sobre un adversario o adversarios específicos. Es más que el ataque y la defensa de la red informática, más eficaz cuando se realiza de forma sincronizada y coherente, por lo que la gestión del conocimiento lo complementa bien. Todos los componentes de una organización, así como en toda la empresa, deben ser incluidos en un plan de acción. El propósito de la guerra de información es controlar o influir en las acciones del tomador de decisiones. Un área de control puede manipularse directamente, mientras que un área de influencia solo puede manipularse indirectamente. El control y la influencia son la esencia del poder (Khan, 2013, p. 142).

De acuerdo con Cronin y Crawford (1999), la guerra de información es la penetración silenciosa de los sistemas de información y 
comunicaciones del objetivo para manejar las percepciones, dar forma a las opiniones, fomentar el engaño y participar en la guerra epistemológica (p. 258). La guerra de influencia y manipulación de la información (information/influence warfare and manipulation [IIWAM]) es el uso deliberado de información por una parte de un adversario para confundir, engañar y, en última instancia, influir en las decisiones que hace el adversario. La IIwAm es una actividad no cinética hostil (Lin y Kerr, 2017).

La guerra informática es, en pocas palabras, un subconjunto de operaciones de información que puede definirse como las acciones que se realizan con el fin de alterar la información y los sistemas de información del adversario, mientras se protege la información y los sistemas de información propios. Tales operaciones abarcan, prácticamente, toda medida cuyo objetivo sea descubrir, alterar, destruir, interrumpir o transferir datos almacenados, procesados o transmitidos por una computadora. Pueden efectuarse en tiempo de paz, durante una crisis o en las etapas estratégica, operativa o táctica de un conflicto armado. El logro del propósito mencionado se obtendrá a través de la superioridad informática, ya sea contando con una tecnología superior, ya sea haciendo un empleo más adecuado de las facilidades informáticas propias (López, 2007, p. 219).

El espacio de batalla es el entorno de información, el cual es el agregado de individuos, organizaciones y sistemas que recogen, procesan, difunden o actúan sobre la información. Tiene tres dimensiones interrelacionadas: física, informacional y cognitivo-emocional, en y por medio de las cuales los individuos, las organizaciones y los sistemas interactúan continuamente. El escenario físico está compuesto por los sistemas de mando y control, software, tomadores de decisiones clave y la infraestructura. La dimensión informacional es específicamente donde la información es recolectada, procesada, almacenada, diseminada y protegida. Por último, la dimensión cognitivo-emocional comprende las mentes y emociones de aquellos que transmiten, reciben, responden o actúan respecto de la información (Lin y Kerr, 2017).

Las operaciones de este tipo de guerra usualmente aprovechan los sesgos cognitivos en los seres humanos. Estos sesgos resultan del uso humano de estrategias de razonamiento intuitivo en lugar de estrategias 
analíticas. Una de las estrategias de razonamiento intuitivas más importantes son las heurísticas, que sustituyen los juicios simples por tareas inferenciales complejas, lo que da lugar a sesgos cognitivos que a veces conducen a conclusiones erróneas. Los sesgos cognitivos sugieren cómo los juicios y las conclusiones de los seres humanos reales pueden diferir de los de una hipotética persona absolutamente racional debido a la dependencia de la heurística mental falible. Pero los factores emocionales también afectan los juicios y las conclusiones que la gente hace. Los sesgos emocionales se pueden ver cuando un individuo tiene una motivación para creer en una respuesta o un resultado particular o una visión que le impide alcanzar los beneficios de la consideración racional (Lin y Kerr, 2017).

Una meta de la guerra de información puede ser la penetración silenciosa del sistema de información y comunicaciones del objetivo para dar forma a las percepciones de la comunidad, fomentar el engaño o la incertidumbre (Cronin y Crawford, 1999, p. 258). La guerra de la información busca evitar la necesidad de recurrir a la fuerza letal poniendo enemigos en posiciones en las que sus recursos de información son inútiles o, peor, poco fiables. En este sentido, aspira a realizar el famoso dicho de Sun Tzu que afirma que someter al enemigo sin luchar es el punto álgido de habilidad (Miller, 1997, p. 158).

La opción de emprender una guerra (clásica) suele implicar un compromiso sustancial, ya que tiene fuertes costos económicos y políticos, sobre todo para la sociedad civil. Estas características de la guerra han sido radicalmente cambiadas por el advenimiento de la guerra de información, que proporciona los medios para llevar a cabo la guerra de una manera completamente diferente. En este escenario, los cambios determinados son de una importancia asombrosa, ya que se refieren tanto a la forma en que los militares y los políticos consideran la guerra y la forma en que se percibe esta en la sociedad civil. Al igual que la guerra tradicional, la guerra de información es muy potente y potencialmente perturbadora. Sin embargo, a diferencia de la guerra tradicional, reduce a la mínima expresión el derramamiento de sangre, es rentable y no es un fenómeno específicamente militar (Taddeo, 2012b, p. 112).

Las operaciones se caracterizarán por la superioridad en la obtención de información en cantidad y calidad, lo que generará un mayor 
poder de combate al enlazar a los sensores, los comandantes y los sistemas de armas para lograr una apreciación compartida de la situación, mayor capacidad de mando, un ritmo de operaciones más elevado, mayor letalidad y mayor supervivencia. Además, resulta necesario evaluar los conocimientos y los factores psicológicos como componentes de la relación de fuerzas (López, 2007, p. 220).

Se puede hablar de tres clases de guerra de información. La primera clase describe ataques contra la privacidad electrónica de un individuo. Esto incluye la divulgación de registros digitales y entradas de bases de datos dondequiera que se almacene la información. La persona promedio hoy en día tiene poco control sobre la información almacenada. La segunda clase describe la competencia, mejor dicho, la guerra de hoy entre las corporaciones alrededor del mundo y el robo de información con fines económicos; no es solo acerca de la adquisición de información, también es posible difundir información, real o ficticia. Y la guerra informática global trabaja contra industrias, fuerzas económicas globales o contra países o Estados enteros. No se enfoca mucho en los datos de investigación de un competidor, sino en el robo de secretos y luego en convertir esta información en contra de sus propietarios (Haeni, 1997).

Cuatro procesos interrelacionados apoyan las operaciones de información defensiva: la protección del ambiente de la información, la detección del ataque, la restauración de la capacidad y la respuesta del ataque. Se llevan a cabo en toda la gama de operaciones militares en todos los niveles de la guerra para lograr los objetivos de la misión. Las operaciones ofensivas de información podrían incluir la recopilación activa de información sobre sistemas de información, intrusiones no autorizadas en sistemas de información, introducción de vulnerabilidades en sistemas informáticos, corrupción o negación de datos e inhabilitación o destrucción de sistemas de información (Joyner y Lotrionte, 2001, p. 835).

Empleada ofensivamente, la guerra de información resalta la manipulación de los sistemas electrónicos de información para influir en las percepciones y el comportamiento de un adversario. Esto podría, por ejemplo, implicar la inhabilitación de sistemas militares y civiles de telecomunicaciones a través de virus informáticos. Defensivamente, 
la guerra de información requiere una capacidad para detectar y frustrar los intentos de manipular las propias fuentes de información. En el ámbito militar, esto implica asegurar la integridad de los sistemas de mando y control, comunicaciones e inteligencia. También deben protegerse los elementos críticos de la infraestructura civil, como las redes eléctricas, las redes financieras y los sistemas de telecomunicaciones. Además, también postula una capacidad para contrarrestar la propaganda y la desinformación enemigas (Miller, 1997, p. 158).

Se puede clasificar en seis subáreas preexistentes que recientemente se han agrupado bajo el título de guerra de información: seguridad operativa, guerra electrónica (electronic warfare [Ew]), operaciones psicológicas (psychological operations [PSYOP]), engaño, ataques físicos a procesos de información y ataques a procesos de información. Por tanto, la guerra de información ofensiva consiste en la unión de las seis anteriores (Nichiporuk, 1999, p. 180).

La guerra electrónica abarca los conceptos tradicionales de interferencia y falsificación de radares y enlaces de comunicación de radio. Las PSYOP son sobre todo el uso de la diseminación de información para debilitar la moral del enemigo y, en última instancia, para romper su voluntad de resistir. El engaño implica el empleo de medios físicos o electrónicos para camuflar la propia postura de la fuerza en el teatro. El ataque físico es el acto de dañar físicamente o destruir los medios de un adversario de recopilar, procesar y organizar la información. Por último, el ataque informativo implica el uso de tecnología informática para cerrar electrónicamente, degradar, corromper o destruir los sistemas de información de un enemigo en el teatro (Nichiporuk, 1999, p. 181).

Se está desarrollando un fenómeno cibernético en evolución: el concepto de operaciones cibernéticas psicológicas (cyber psychological operations [CYOP, pronunciado "PSYOP"]), que son aquellas que atacan e influyen directamente en las actitudes y los comportamientos de soldados y la población en general. Mientras los ejércitos continúan compitiendo en el espacio de batalla digital, las poblaciones locales están ahora atrapadas en batallas espaciales de influencia digital. Las CYOP también están inundadas de consecuencias no deseadas, ya que se ha empezado a entender qué grado de influencia, persuasión, engaño y movilización ofrece el entorno cibernético (Thomas, 2007, p. 30). 
Las CYOP se caracterizan por su velocidad, precisión y creatividad. La velocidad se reconoce debido a la rapidez del mecanismo de respuesta de mensajes. Un incidente ocurre y se informa en internet, o por teléfono celular o mensajería de video, antes de que los servicios legítimos de noticias puedan adjudicar su autenticidad. En particular, estos mensajes tienen un alcance infinito, aunque preciso. Se puede dirigir a soldados o enemigos y poblaciones con igual facilidad. Además, la creatividad es un tema emergente. Las tecnologías ofrecen la capacidad de actualizar las técnicas PSYOP probadas con tiempo usando nuevas aplicaciones no probadas o probadas (Thomas, 2007, p. 30).

Se han identificado cinco capacidades básicas para la realización de operaciones de información: 1) operaciones psicológicas, 2) engaño militar, 3) seguridad de operaciones, 4) operaciones de redes de computadoras y 5) guerra electrónica. Estas capacidades están diseñadas para influir en los responsables de tomar decisiones en el extranjero y proteger la toma de decisiones, así como para afectar o defender el espectro electromagnético, los sistemas de información y la información que apoya a los tomadores de decisiones, sistemas de armas, mando y control y respuestas automatizadas (Wilson, 2004).

Las PSYOP se definen como operaciones planificadas para transmitir información e indicadores seleccionados a audiencias extranjeras con el fin de influir en sus emociones, motivaciones, razonamiento objetivo y, en última instancia, el comportamiento de gobiernos, organizaciones, grupos e individuos extranjeros. El propósito de las PSYOP es inducir o reforzar actitudes y comportamientos ajenos a los objetivos del originador (Peña, Casas y Mena, 2009). El engaño guía a un enemigo a cometer errores presentando información, imágenes o declaraciones falsas. El engaño militar se define como acciones ejecutadas para engañar deliberadamente a los responsables militares adversarios con respecto a capacidades militares, intenciones y operaciones amistosas, haciendo que el adversario tome acciones específicas (o inacciones) que contribuyan al éxito de la operación militar amistosa (Wilson, 2004).

La seguridad operacional (security operations [OPSEC]) se define como un proceso de identificación y análisis de la información que es crítica para las operaciones e incluye 1) identificar qué información 
puede ser observada por los sistemas de inteligencia del adversario, 2) determinar indicadores que los sistemas hostiles de inteligencia podrían reunir a fin de obtener información crítica a tiempo para ser útil a los adversarios y 3) seleccionar y ejecutar medidas que eliminen o reduzcan la vulnerabilidad de las acciones a la explotación del adversario (Wilson, 2004).

Las operaciones de red informática están compuestas de tres áreas de misión específicas pero complementarias. Implican la capacidad de atacar e interrumpir las redes informáticas enemigas, proteger los sistemas de información militar y explotar las redes informáticas enemigas a través de la recolección de inteligencia. El ataque a redes de computadoras se define como las operaciones para interrumpir, negar, degradar o destruir la información residente en los ordenadores y redes de ordenadores, o las computadoras y las redes en sí. La defensa de redes de computadoras se define como medidas defensivas para proteger y defender la información, computadoras y redes de interrupción de la negación, degradación o destrucción. La explotación de redes de computadoras involucra el espionaje, que en general se realiza a través de herramientas de red que penetran en los sistemas adversos para devolver información o copias de archivos que, individual o colectivamente, permiten a los militares obtener una ventaja sobre el adversario (Wilson, 2004).

La guerra electrónica se define como cualquier acción militar que involucre la dirección o el control de la energía del espectro electromagnético para engañar o atacar al enemigo. La guerra electrónica ha sido un componente importante de las operaciones aéreas militares desde los primeros días del radar, y los ingenieros y científicos han desarrollado los conceptos para incluir ahora nuevas técnicas de sigilo (Wilson, 2004).

Se han enumerado cinco principios de la guerra de información:

- negación;

- mejora de fuerza;

- conciencia situacional de supervivencia; 
- comando, control y comunicaciones;

- nivel (Sulaiman, 2005).

La información sobre la fuerza y debilidad del enemigo y las fuerzas propias es importante para ganar una guerra. La negación de esa información a los comandantes enemigos los pondría en la oscuridad. Por tanto, los centros de mando y control y los sistemas de apoyo a la toma de decisiones y comunicaciones deben ser los objetivos principales y todos los sensores hostiles deben ser suprimidos o destruidos antes de participar en combate (Sulaiman, 2005).

El segundo principio es la mejora de la fuerza. Las tropas sobre el terreno necesitan la información tanto como sus comandantes. El flujo de información de arriba abajo debe ser lo más sutil posible para reducir o evitar riesgos adicionales para las tropas (Sulaiman, 2005).

La descentralización es importante para garantizar la supervivencia. La política y la estrategia deben centralizarse en el nivel superior, pero se debe dar un margen de maniobra al nivel inferior para planificar y ejecutar sus misiones. La interoperabilidad es otro aspecto para asegurar la supervivencia. Todo el sistema de información y comunicación debe ser capaz de hablar entre sí para permitir el máximo intercambio de información (Sulaiman, 2005). El último principio de la guerra de la información es el nivel, según el cual toda la tecnología disponible debe ser usada contra las capacidades materiales e inmateriales del enemigo. La intensidad de los conflictos de la guerra de información debe contener todos los esfuerzos.

La guerra psicológica abarca el uso de información contra la mente humana. Hay cuatro categorías de guerra psicológica: 1) operaciones contra la voluntad nacional, 2) operaciones contra comandantes opuestos, 3) operaciones contra tropas y 4) conflicto cultural (Libicki, 1998, p. 34).

El elemento cibernético permite que las operaciones psicológicas penetren no solo unos cuantos kilómetros en el territorio enemigo, sino que lleguen directa y profundamente a las casas de las poblaciones objetivo. El elemento cibernético lo hace en privado y en silencio, e invade no solo las computadoras y los teléfonos celulares, sino también el bienestar psicológico de la población (Thomas, 2007, p. 30). 
En la actualidad, se dispone de una amplia variedad de herramientas de guerra de información, tanto defensiva como ofensivamente, para llevar a cabo ataques de este tipo. Estas armas incluyen:

- Un sniffer, ejecutado desde un sitio remoto por un intruso, que permitiría a este recuperar usuarios y contraseñas a medida que atraviesa la red. Se tiene así acceso a información sensible relacionada con la defensa nacional, información corporativa o secretos comerciales.

- Un caballo de Troya, instalado de forma remota, que permite a un extraño controlar la red y causar que funcione mal en el comando.

- Una puerta trampa, utilizada para obtener acceso y control no autorizado de los sistemas de control (Joyner y Lotrionte, 2001, p. 836).

- Un virus, que es un fragmento de código que se copia en un programa más grande y lo modifica. Un virus se ejecuta solo cuando el programa donde fue instalado comienza a ejecutarse. El virus se replica entonces e infecta otros programas a medida que se reproduce.

- Un gusano, que es un programa independiente. Se reproduce copiándose a sí mismo de una computadora a otra, por lo general a través de una red. A diferencia de un virus, no modifica otros programas.

- Una bomba, que es un tipo de caballo de Troya, usado para liberar un virus, un gusano o algún otro ataque al sistema. Es un programa independiente o un pedazo de código que ha sido plantado por un desarrollador del sistema o programador (Haeni, 1997).

Paralelamente, en la medida en que la naturaleza de las tecnologías informáticas se fundamentó en su capacidad de transmitir datos (multimedia) por todo el planeta, que transgrede las barreras espaciotemporales a través de internet, la organización y doctrina de los ejércitos 
obtuvo nuevas capacidades para plantearse modelos de doctrina, organización, movilización y operaciones de prolongación planetaria.

El elemento que mayor relevancia denota en este acápite de colofón es el valor que obtuvo la información durante 1990 y 1997. Se hace referencia al hecho de que, aceptando que la información fue uno de los catalizadores del proceso de transformaciones reseñado (el otro factor fue la tecnología), no perdió en ningún sentido su carácter de "complemento" para hacer la guerra.

Aunque mediante las operaciones de la información se plantearon formas de actuar por medio de los ataques informáticos a los sistemas del adversario, precisamente nunca sobrepasaron la lógica de romper el vínculo de este actor con su información y la capacidad de recepción, procesamiento y difusión de esta. Por esto, debe recordarse que su objetivo es llegar a la mente del rival y desmoralizarlo a través de la manipulación de la comunicación. En tal distinción, radica el hecho de que en este capítulo no se aborde aún el estudio de fenómenos como la ciberguerra.

Bajo esta tipología de guerra, que bien podría considerarse como una generación más avanzada de la guerra de la información, aunque también se emplean ataques informáticos, como su nombre lo indica, es un combate de carácter cibernético o de control. Y ya no se busca dejar al enemigo sin la información que le permite actuar doctrinalmente, sino que se atacan los sistemas informáticos de control y funcionamiento.

Se trata de atacar los pivotes de un Estado nación para paralizarlo o destruir parte de este, tan solo empleando computadoras para transmitir la información hasta los sistemas que controlan, por ejemplo, la infraestructura crítica del Estado o hurtar secretos nacionales y así poner en peligro la subsistencia de una sociedad.

En enero de 1998, por ejemplo, las tensiones surgieron entre los Estados Unidos e Irak en relación con los inspectores de armas de la Organización de Naciones Unidas (ONU). Saddam Hussein expulsó a los inspectores de la ONU de Irak, lo que precipitó una crisis y empujó a los Estados Unidos al borde de una nueva acción militar en el golfo Pérsico. El primer lunes de febrero, los analistas del Centro Nacional de Monitoreo de Computadoras de la Fuerza Aérea (NORAD) detectaron una serie inusual de banderas de advertencia rojas en sus pantallas que indicaban intrusiones no autorizadas en por lo menos seis redes 
electrónicas en todo el país. Varias decenas de sistemas informáticos en instalaciones militares y de gobierno de los Estados Unidos fueron comprometidos con éxito por intrusos, lo que provocó una respuesta a gran escala del Departamento de Defensa de los Estados Unidos (United States Department of Defense [DoD]), conocida ahora como operación Solar Sunrise. El ataque contra los sistemas informáticos violó sistemas pertenecientes a la Marina y la fuerza aérea, así como a los laboratorios de investigación financiados por el Gobierno federal (Joyner y Lotrionte, 2001, p. 839).

Los sistemas tecnológicos avanzados deberían magnificar los tipos de efectos psicológicos producidos por la campaña aérea de la coalición contra las fuerzas terrestres iraquíes durante la guerra del Golfo Pérsico. La campaña aérea intensificó las deficiencias en la motivación y la moral, ya presentes en las filas iraquíes antes del estallido de las hostilidades, por 1) convencer a los oficiales iraquíes y alistados de la supremacía aérea de la coalición, 2) probar la insuficiencia de la defensa aérea iraquí, 3) confirmar la inevitabilidad de la derrota iraquí, 4) intensificar las penurias de las tropas iraquíes y 5) aumentar los temores de los soldados iraquíes sobre su supervivencia personal y la seguridad de sus familias en el país (Hosmer, 1999, p. 234).

Durante la Operación Libertad Iraquí (Operation Iraqi Freedom [OIF]), se dejaron caer panfletos que llevaban el mensaje oficial: "Cualquier guerra no es contra el pueblo iraquí, es para desarmar a Hussein y poner fin a su Gobierno”. Mensajes de difusión similares fueron enviados desde el Air Force EC-130E, y de los buques de la Marina que operan en el golfo Pérsico. Las fuerzas estadounidenses también enviaron una avalancha de correos electrónicos, faxes y llamadas telefónicas a numerosos líderes iraquíes que los alentaban a abandonar el apoyo a Saddam Hussein (Wilson, 2004).

En un ataque a los estadounidenses, los agresores accedieron a los sistemas de logística, administración y contabilidad clasificados que controlaban la capacidad de los Estados Unidos de manejar y desplegar sus fuerzas militares. Obtuvieron acceso privilegiado a las computadoras mediante el uso de herramientas disponibles en un sitio web de una universidad e instalaron programas sniffer para recopilar contraseñas del usuario. Además, crearon una puerta trasera para volver a 
entrar en el sistema en cualquier momento y luego utilizaron un parche disponible en un sitio web de la universidad para cerrar la vulnerabilidad (Joyner y Lotrionte, 2001, p. 840).

En octubre de 1999, Mitchael A. Vatis, director del Centro Nacional de Protección de Infraestructuras (National Infrastructure Protection Centre [NIPC]) del Federal Bureau of Investigation (FBI), testificó ante un subcomité del Senado la primera confirmación pública sobre la investigación del FBI realizada durante todo un año, llamada Moonlight Maze. Esta reveló el ataque de computadora más extenso dirigido al Gobierno de los Estados Unidos. Según los informes, los piratas informáticos que trabajan desde Rusia penetraron en las computadoras del DoD durante más de un año y robaron grandes cantidades de información confidencial. Los expertos en seguridad descubrieron por primera vez las insinuaciones en enero de 1999 cuando los investigadores de la fuerza aérea y del departamento de crimen informático del Ejército rastrearon los ataques a un proveedor de servicios de internet en Rusia. Según los funcionarios del Pentágono y del FBi, la piratería fue una campaña de inteligencia rusa patrocinada por el Estado para descubrir la tecnología estadounidense, no solo apuntando al DoD, sino también al Departamento de Energía (United States Department of the Energy [DOE]), a la Administración Nacional para la Aeronáutica y el Espacio (National Aeronautics and Space Administration [NASA]), y a contratistas y universidades militares vinculadas (Joyner y Lotrionte, 2001, p. 840).

Experimentos con el uso de la guerra de información ocurrieron durante la crisis de Kosovo. El 30 de marzo de 1999, tres días después de que la Organización del Tratado del Atlántico Norte (OTAN) comenzara sus misiones de bombardeo sobre Serbia y Kosovo, los hackers iniciaron un programa coordinado para interrumpir el sistema de comunicaciones por correo electrónico de la OTAN al sobrecargarlo. Aunque las identidades de los hackers no fueron determinadas, las autoridades occidentales sospechan que eran miembros de la Crna Ruka que atacaron el sitio web de información de Kosovo en octubre de 1998 (Joyner y Lotrionte, 2001, p. 842).

Grupos como Al Qaeda e Hizbulá han desarrollado CYOP de su propio género. Estos grupos tratan de cambiar actitudes y 
comportamientos a través de la intimidación, el temor cibernético o el odio racial o religioso. Por supuesto, su CYOP no solo está dirigido hacia afuera, sino también al interior de su población. A menudo, se dirige a los descontentos en el Medio Oriente, tratando de reclutar a aquellos que se sienten privados de sus derechos. Las fuerzas de la coalición no han realizado suficientes esfuerzos para neutralizar estas actividades terroristas/insurgentes en Irak y Afganistán como cabría de esperarse. La doctrina de operaciones informáticas de los Estados Unidos es débil (de hecho, casi inexistente) en la cuestión de la contrapropaganda, lo cual se refleja en las operaciones de la coalición ${ }^{39}$. (Thomas, 2007, p. 32)

El líder del clan somalí Mohamed Fará Aidid parece ser un maestro de los usos de la guerra psicológica. En un enfrentamiento que costó la vida de diecinueve soldados estadounidenses, el lado de Aidid perdió quince veces ese número, aproximadamente un tercio de su fuerza. Las fotografías de los somalíes arrastrando cadáveres de soldados estadounidenses por las calles de Mogadiscio transmitidas por CNN en los Estados Unidos terminaron convenciendo a las audiencias de televisión en ese país que no debían permanecer en Somalia. Las fuerzas estadounidenses se fueron, y Aidid, en esencia, ganó la guerra de la información (Libicki, 1995, p. 35).

Durante la revolución egipcia de 2011, las fuerzas gubernamentales del presidente Hosni Mubarak apagaron internet en lo que pudo verse como un intento de control cibernético total. Como la herramienta más fuerte de los revolucionarios estaba en el ciberespacio, el objetivo del Gobierno era evitar que los manifestantes en la plaza Tahrir y otros sitios alrededor de Egipto se comunicaran con las audiencias locales, regionales y globales, lo que influyó en su decisión de actuar. En la noche del 27 al 28 de enero, en lo que el Gobierno consideró claramente un escenario casi perfecto, las cuatro principales líneas de comunicación en el país eran controladas por el Gobierno y las fuerzas del régimen ordenaron a los proveedores de servicios de internet cerrar toda conectividad (Crowell, 2017, p. 20).

39 Traducción del autor. 
La oposición egipcia disputó con éxito el control cibernético gubernamental. En lo que se puede considerar como una maniobra para lograr objetivos, la oposición egipcia utilizó hábilmente la conectividad selectiva para mover contenido y disputar el control cibernético gubernamental. El uso de la conectividad técnica humana y limitada a través de teléfonos (tanto celulares como fijos) y las redes sociales ayudaron a la oposición egipcia a superar las fuerzas gubernamentales. Las llamadas telefónicas se hicieron al país para averiguar lo que estaba sucediendo, estas fueron grabadas y el contenido fue traducido para luego ser publicado en distintos medios de comunicación social (Crowell, 2017, p. 20).

En 2013, un misterioso grupo de hackers autodenominado The Shadow Brokers robó una serie de discos llenos de secretos de la Agencia de Seguridad Nacional (National Security Agency [NSA]). Desde 2016, han puesto estos secretos a disposición de internet para ser descargados. Han avergonzado públicamente a la NSA y han deteriorado sus capacidades de recopilación de información de inteligencia, al mismo tiempo que han preparado sofisticadas armas cibernéticas y las han puesto en manos de cualquiera que esté interesado en ellas. Además, han expuesto las principales vulnerabilidades en los servidores de enrutadores Cisco, Microsoft Windows y Linux, obligando a esas empresas y sus clientes a enfrentarlos (Schneier, 2017).

En total, el grupo ha publicado cuatro conjuntos de material de la NSA: un conjunto de herramientas de piratería contra los enrutadores, una serie de dispositivos que pueden redirigir datos a través de redes de computadoras y contra servidores de correo, una colección contra Microsoft Windows y un directorio de trabajo de un analista de la NSA que irrumpe la red de la Society for Worldwide Interbank Financial Telecommunication (swIFT) (Schneier, 2017).

\section{El teatro de los centros de gravedad: contra la infraestructura crítica}

Como a la seguridad nacional se le ha asignado la más alta prioridad, el término infraestructura crítica se ha convertido en una importante 
preocupación política. En la Orden Ejecutiva 13010, firmada por el presidente Bill Clinton el 15 de julio de 1996, que establecía la Comisión Presidencial sobre protección de infraestructuras críticas, se hizo alusión a lo que constituye una infraestructura crítica: ciertas infraestructuras nacionales que son tan vitales que su incapacidad o destrucción tendría un impacto debilitante en la defensa o la seguridad económica de los Estados Unidos (Moteff, Copeland y Fischer, 2003, p. 2).

El término infraestructura es evolutivo y a menudo ambiguo. Se define tradicionalmente como cualquier activo físico que puede ser utilizado para producir servicios o para apoyar la estructura y el funcionamiento de una sociedad o empresa. Hoy en día, la noción de infraestructura pública se ha ampliado y abarca estructuras tales como carreteras, puentes, aeropuertos e instalaciones de vías aéreas, sistemas de transporte colectivo, plantas de tratamiento de residuos, instalaciones energéticas, hospitales, edificios públicos e instalaciones espaciales o de comunicación.

El entorno operativo para la infraestructura crítica es cada vez más complejo, impulsado por una serie de factores, que incluyen la globalización, la evolución de la tecnología y la naturaleza interconectada de las cadenas de suministro de infraestructuras críticas, redes y sistemas. Esta complejidad, en particular, afecta la capacidad de entender y manejar las dependencias intersectoriales. Las computadoras, las comunicaciones y las mismas infraestructuras críticas vinculan cada vez más a otras infraestructuras. La interconexión creciente de la red significa que una interrupción en una red puede conducir a la interrupción en otra. Esta dependencia de los ordenadores y las redes aumenta la vulnerabilidad de las infraestructuras críticas a los ataques cibernéticos ${ }^{40}$. (Simon, 2017, p. 2).

El hecho de que las infraestructuras críticas de las naciones estén altamente interconectadas y sean mutuamente dependientes de formas complejas, tanto físicamente como a través de una serie de tecnologías

40 Traducción del autor. 
de la información y de la comunicación (TIC) (los llamados sistemas cibernéticos), es más que un concepto teórico abstracto. Lo que sucede con una infraestructura puede afectar directa e indirectamente a otras infraestructuras, a grandes regiones geográficas, y causar daños a toda la economía nacional y global (Boaru y Badita, 2008, p. 130).

Las dependencias de infraestructura crítica con el ciberespacio se extienden más allá de las fronteras soberanas y se convierten en globales. Estas son áreas en las que un grupo diverso de actores, muchos con muy diversos intereses e incentivos, interactúan y compiten en un espacio predominantemente comercial, entonces, es mucho más que solo los gobiernos; tanto en el sector público como en el privado están íntimamente ligados, les guste o no. Estas interdependencias complejas a nivel mundial están redefiniendo lo que constituye la infraestructura crítica. Ellos desafían los conceptos de soberanía nacional y nos obligan a considerar las tensiones inherentes a un sistema altamente optimizado aún frágil de conexiones físicas, lógicas y sociales ${ }^{41}$. (Clemente, 2013, p. 1).

Identificar, comprender y analizar tales interdependencias son desafíos significativos. Estos desafíos se ven amplificados por la amplitud y complejidad de las infraestructuras nacionales críticas. Estas infraestructuras, que afectan a todos los ámbitos de la vida cotidiana, incluyen la producción y distribución de energía eléctrica, gas natural y petróleo, telecomunicaciones (información y comunicaciones), transporte, abastecimiento de agua, banca y finanzas, servicios de emergencia y gubernamentales, agricultura y otros sistemas fundamentales y servicios que son críticos para la seguridad, la prosperidad económica y el bienestar social de la nación (Boaru y Badita, 2008, p. 131).

Estos vínculos pueden ser físicos, cibernéticos, relacionados con la ubicación geográfica o de naturaleza lógica. Las infraestructuras interdependientes también muestran una amplia gama de características espaciales, temporales, operativas y organizativas, que pueden afectar su capacidad de adaptación a las condiciones cambiantes del sistema.

41 Traducción del autor. 
Y, finalmente, las interdependencias y las tipologías de infraestructura resultantes pueden crear interacciones sutiles y mecanismos de retroalimentación que a menudo conducen a comportamientos no intencionados y consecuencias durante las interrupciones (Boaru y Badita, 2008, p. 132).

Estas dimensiones y sus componentes son descriptivos y están destinados a facilitar la identificación, la comprensión y el análisis de las interdependencias, las cuales varían ampliamente y tienen sus propias características y efectos sobre los agentes de la infraestructura. Se pueden establecer cuatro clases principales de interdependencias: física, cibernética, geográfica y lógica. Aunque cada una tiene características distintas, estas clases de interdependencias no son mutuamente excluyentes:

- Interdependencia física: dos infraestructuras son físicamente interdependientes si el estado de cada una depende de las salidas materiales de la otra. Como su nombre lo indica, una interdependencia física surge de un enlace físico entre los insumos y los productos de dos agentes: una mercancía producida o modificada por una infraestructura (una salida) es requerida por otra infraestructura para que funcione (una entrada). De esta manera, las perturbaciones en una infraestructura pueden irrumpir en otras infraestructuras. En consecuencia, el riesgo de falla o desviación de las condiciones normales de operación en una infraestructura puede ser una función del riesgo en una segunda infraestructura si ambas son interdependientes.

- Interdependencia cibernética: una infraestructura tiene una interdependencia cibernética si su estado depende de la información transmitida a través de la infraestructura de información. Las interdependencias cibernéticas son relativamente nuevas y son el resultado de la generalizada informatización y automatización de las infraestructuras en las últimas décadas. En gran medida, el funcionamiento fiable de las infraestructuras modernas depende de sistemas de control computarizados, desde los sistemas SCADA (supervisory control and data acquisition) que controlan las redes eléctricas hasta los sistemas 
computarizados que gestionan el flujo de vagones y mercancías en la industria ferroviaria. En estos casos, las infraestructuras requieren información transmitida y entregada por la infraestructura de información. En consecuencia, los estados de estas infraestructuras dependen de los productos de la infraestructura de la información. Las interdependencias cibernéticas conectan las infraestructuras entre sí a través de enlaces electrónicos informativos; los productos de la infraestructura de la información son insumos para la otra infraestructura, y el "producto básico" pasado entre las infraestructuras es la información.

- Interdependencia geográfica: las infraestructuras son geográficamente interdependientes si un evento ambiental local puede crear cambios de estado en todas ellas. Una interdependencia geográfica se produce cuando elementos de múltiples infraestructuras están en estrecha proximidad espacial. Dada esta proximidad, eventos como una explosión o un incendio podrían crear alteraciones o cambios correlacionados en estas infraestructuras geográficamente interdependientes. Tales cambios correlacionados no se deben a conexiones físicas o cibernéticas entre infraestructuras, sino que surgen de la influencia que el evento ejerce sobre todas las infraestructuras simultáneamente. Nótese que más de dos infraestructuras pueden ser geográficamente interdependientes en función de su proximidad física.

- Interdependencia lógica: dos infraestructuras son lógicamente interdependientes si el estado de cada una depende del estado de la otra a través de un mecanismo que no es una conexión física, cibernética o geográfica. Las interdependencias lógicas pueden ser comparadas más estrechamente a un esquema de control que conecta un agente en una infraestructura a un agente en otra infraestructura sin ninguna conexión física, cibernética o geográfica directa (Boaru y Badita, 2008).

Una infraestructura crítica se identifica a menudo como una infraestructura cuyo funcionamiento incorrecto, incluso durante un periodo limitado, puede afectar la economía de individuos o grupos individuales, 
con pérdidas económicas e, incluso, exponer a personas y cosas a un riesgo de seguridad (Montanari y Querzoni, 2014, p. 5).

Las infraestructuras críticas son esencialmente procesos físicos controlados por computadoras en red. Son, por lo general, tan vulnerables como cualquier otro sistema informático interconectado, pero su fracaso tiene un alto impacto socioeconómico. Internet hoy es una red de dispositivos sofisticados, fibras y señales electromagnéticas, que interconectan los sistemas computacionales y electrónicos de todo el mundo e hicieron que la sociedad y la economía mundial evolucionaran. Sin embargo, los límites de esta web están ampliando su alcance a las infraestructuras físicas, como la energía, el agua, el gas, el petróleo y el transporte. Por tanto, la amenaza ya no es contra los sistemas con un valor económico limitado, sino contra las infraestructuras que soportan la vida moderna ${ }^{42}$. (Bessani, Sousa, Correia, Neves y Veríssimo, 2008, p. 18)

Existen numerosas definiciones nacionales e internacionales de la infraestructura crítica. Aunque las similitudes entre las definiciones tienden a pesar más que sus diferencias, los matices son reveladores. Un informe de la Asamblea Parlamentaria de la OTAN señala que en algunos países esos criterios destacan la finalidad o el propósito de la infraestructura (es decir, la infraestructura es fundamental, ya que realiza una función que es vital para la sociedad), mientras que en otros subrayan la gravedad de los efectos de la interrupción o destrucción de una infraestructura determinada en la sociedad (es decir, la infraestructura es fundamental, ya que su pérdida sería muy perjudicial) (Clemente, 2013, p. 13).

Una de las razones por las que la seguridad de las infraestructuras críticas es una cuestión compleja y urgente es que existen varios actores, como los siguientes, que representan una amenaza, posiblemente más que en los sistemas informáticos tradicionales:

1. Los Estados nación son un conjunto importante de actores en el paisaje de los ciberataques contra las infraestructuras críticas.

42 Traducción del autor. 
Su importancia deriva del hecho de que son los propietarios de estas estructuras, las cuales son el objetivo más relevante en la ciberguerra moderna. Una extensión de esta categoría de actores incluye aquellos atacantes que son patrocinados por Estados nacionales, es decir, un sujeto externo pagado o apoyado por los gobiernos de la nación para comprometer las infraestructuras críticas de otra nación.

2. Los grupos de amenaza organizados no estatales en general etiquetados como "ciberterroristas" también están causando amenazas. El potencial de la guerra asimétrica se deriva de la facilidad de atacar las infraestructuras críticas a través de medios de guerra cibernética (Montanari y Querzoni, 2014).

Los actores antes mencionados están impulsados por dos amplias categorías de motivaciones:

- Guerra política y estratégica: de la cantidad de información confiable que circula en relación con los ataques contra infraestructuras críticas, se puede concluir que la mayoría de los ataques tienen motivaciones estratégicas. Otro tipo de ataque tiene el objetivo de filtrar información secreta. Por el momento, no se puede establecer con certeza cuál es el uso final de dicha información; sin embargo, se puede argumentar que las principales motivaciones son de naturaleza política. Actores como Estados nacionales y hacktivistas caen en esta categoría.

- Financiera: los actores orientados a los negocios y los Estados nacionales también están impulsados por razones económicas. Esta categoría de motivación ha existido siempre. Sin embargo, golpear la infraestructura crítica valiosa puede resultar en un impacto financiero sustancialmente más alto que golpear a los sistemas tradicionales de tecnologías informáticas (Montanari y Querzoni, 2014).

Las redes informáticas de soporte inciden directamente en el funcionamiento de los sistemas de infraestructura como agua, alcantarillado, energía eléctrica. Estos, además de la gestión del transporte 
público, se engloban en una categoría conocida como sistemas de control industrial (industrial control system [ICS]). Esta categoría incluye "varios tipos de sistemas, como el control de supervisión y adquisición de datos (supervisory control and data acquisition [SCADA]), sistemas de control distribuido (distributed control system [DCs]) y los controladores lógicos programables (programmable logic controller [PLC]), todo diseñado para gestionar los equipos industriales esenciales para los servicios prestados" (Reu, Shakarian y Shakarian, 2013, p. 200).

Identificar, entender y analizar las interdependencias entre infraestructuras ha adquirido una importancia creciente en la última década. Los cambios tecnológicos, económicos y regulatorios han alterado radicalmente las relaciones entre las infraestructuras, y la revolución de la tecnología de la información ha dado lugar a lo esencial de las infraestructuras más interconectadas y complejas en general con mayor centralización del control (Rinaldi, Peerenboom y Kelly, 2001, p. 24). De hecho, la tendencia hacia una mayor interdependencia de la infraestructura se ha acelerado y muestra pocas señales de disminuir.

La comunidad de la infraestructura crítica incluye a los propietarios y operadores públicos y privados, y a otras entidades con un papel dentro de la infraestructura de la nación. Los miembros de cada sector de la infraestructura crítica realizan funciones que son compatibles con la tecnología de la información (TI) y los ICs. Esta dependencia de la tecnología, la comunicación y la interconectividad de las TIC y los ICs ha cambiado y ampliado las posibles vulnerabilidades y un mayor riesgo potencial de operaciones. Como los sistemas de control industrial y los datos producidos en operaciones de ICS se utilizan cada vez más para entregar servicios críticos y apoyar las decisiones de negocios, el impacto potencial de un incidente de seguridad cibernética en una organización empresarial, los activos, la salud y la seguridad de las personas y el medioambiente deben ser considerados (National Institute of Standards and Technology, 2014, p. 3).

La ciberguerra se ha convertido en un peligro actual con el descubrimiento del gusano Stuxnet en junio de 2010, el cual fue pionero en el ataque coordinado contra la infraestructura crítica o los sistemas de control de una nación. Los ataques clandestinos estadounidenses contra 
los sistemas informáticos de las instalaciones iraníes de enriquecimiento nuclear en 2012, así como los ataques cibernéticos rusos contra los sitios web y las infraestructuras de redes de Estonia y Georgia, se clasifican como tácticas de la ciberguerra (Simon, 2017, p. 4).

Mientras transcurría abril de 2007, se desarrolló una pequeña disputa interna entre el Gobierno estonio y los habitantes rusos en este país por un monumento soviético ubicado en la capital (The Economist, 2007). Esta tensión condujo, aparentemente, a que el país europeo fuese víctima de un ataque a su infraestructura de información, que sentó precedentes al ser el primer ataque cibernético que se ha dirigido a la seguridad nacional de un país (Ashmore, 2009, p. 4). Los daños se dieron, principalmente, en los sitios web del Gobierno y de los bancos, que sustituyeron la información oficial y lograron la incomunicación y problemas para cumplir con sus funciones.

Para mayo, los ataques ya eran graves, los cuales llegaron a causar una disfunción total, tanto para los trabajadores del Gobierno que querían comunicarse como para los usuarios de páginas de compras y de libre acceso. Esto se extendió por un par de días y causó problemas tanto políticos como económicos (The Economist, 2007).

El ataque Distributed Denial of Service (DDos) fue dirigido con éxito a los sitios web de todos los ministerios del Gobierno, dos de los principales bancos y varios partidos políticos. Los hackers fueron, incluso, capaces de desactivar el servidor de correo electrónico parlamentario y desactivar tarjetas de crédito y cajeros automáticos. Uno de los bancos de Estonia víctima de los ataques calculó las pérdidas estimadas del ciberataque en alrededor de un millón de dólares en daños y perjuicios (Kozlowski, 2014, p. 248).

El 20 de julio de 2008, la página web del presidente georgiano fue objeto de un ataque de denegación de servicio cibernético. El ataque cerró la página web durante 24 horas y fue un precursor de un ataque cibernético más grande que vendría menos de un mes más tarde. El 8 de agosto de 2008, un ataque de denegación de servicio coordinado se hizo en contra de los sitios web del Gobierno de Georgia, al mismo tiempo que las fuerzas rusas estaban comprometidas en el combate con las fuerzas georgianas. A medida que los ataques terrestres aumentaron lo hicieron los ataques cibernéticos. Esta fue la primera vez 
que un ataque cibernético fue realizado en conjunto con el conflicto armado (Ashmore, 2009, p. 20).

Había transcurrido poco más de un año cuando otro país de la región se vio afectado en el sector informático. Georgia vio cómo, mientras enfrentaba una guerra tradicional contra el Ejército ruso por Osetia, sus páginas web militares y políticas eran paralizadas (Korns y Kastenberg, 2009). Las intenciones más probables de este ataque era desinformar a la comunidad y desestabilizar las capacidades de mantener el orden por parte del Gobierno, lo que traería a su vez como consecuencia una disminución en la habilidad de responder ante el conflicto físico en la frontera ruso-georgina (Kuehl, 2009).

El ataque ruso en redes militares y gubernamentales a Georgia tuvo un gran éxito. $\mathrm{Al}$ parecer, 54 sitios web en Georgia relacionados con las comunicaciones, las finanzas y el Gobierno fueron atacados por elementos corruptivos desde Rusia. Así como tanques y tropas estaban cruzando la frontera y misiones de bombarderos sobrevolaban, los ciudadanos georgianos no podían acceder a los sitios web para obtener información e instrucciones. Las autoridades de Georgia descubrieron que su acceso a internet y las redes de comunicación eran excepcionalmente vulnerables a la interferencia de Rusia ${ }^{43}$. (Hollis, 2011, p. 2)

Con el fin de la primera década del siglo xxi, llegó un momento trascendental en el ámbito de la guerra cibernética. Los investigadores de seguridad de VirusBlockAda encontraron un malware en una planta de tratamiento de uranio en Irán, un gusano informático denominado Stuxnet, diseñado exclusivamente para hacer funcionar incorrectamente cualquier equipo industrial que se viera infectado. Este ataque fue catalogado por expertos en seguridad informática como un acontecimiento sin precedentes (Shakarian, 2011, p. 50).

Esta herramienta tecnológica entró en el sistema por un procesador a través de conexiones de USB, y se difundió con impresionante velocidad, llegando a países como China y la India (Kuehl, 2009).

43 Traducción del autor. 
Fue programado para buscar los sistemas informáticos que estaban al mando del reactor nuclear de Bushehr. Quienes se encargaron dentro del Gobierno iraní de investigar el fenómeno tuvieron que mantener bajo absoluta reserva el alcance definitivo de Stuxnet, por lo que a partir de este punto no hubo más que desinformación (Kerr, Rollins y Theohary, 2010). Hasta ese momento el gusano era, por lejos, el arma más potente en el escenario cibernético:

El incidente dañó casi 1000 tubos de centrifugación en la instalación iraní de Natanz. Esta cifra es significativa a la luz del número total de tubos instalados (9000) y la porción de los alimentados con uranio (4000). Una disminución del $23 \%$ en el número de centrifugadoras de funcionamiento desde mediados de 2009 hasta mediados de 2010 puede haber sido debido al ataque Stuxnet ${ }^{44}$. (Gamero-Garrido, 2014, p. 22)

Al 25 de septiembre de 2010, Irán había identificado las direcciones IP de 30000 sistemas informáticos industriales que habían sido infectados por Stuxnet, según Mahmoud Liaii, director del Consejo de Tecnología de la Información de Industrias y Minas del Ministerio de Irán, quien argumentó que el virus está diseñado para transferir datos sobre las líneas de producción de las plantas industriales a lugares fuera de Irán (Kerr, Rollins y Theohary, 2012, p. 3). Es posible asegurar que antes de Stuxnet no había sucedido un ataque con un impacto semejante. Desde un principio, mantuvo como objetivo la infraestructura crítica nuclear iraní (Porteus, 2010), y por primera vez, un ataque diseñado y ejecutado exclusivamente en el ciberespacio tuvo alcances reales y físicos.

El hacktivismo surgió a finales de la década de 1980 en forma de virus de internet y gusanos de propagación con propaganda política y mensajes de protesta. El grupo Worms Against Nuclear Killers (WANK) es un ejemplo de hacktivismo temprano; en 1989, estos hacktivistas antinucleares con sede en Australia instalaron gusanos en las redes de la NASA y el DOE para protestar por el lanzamiento de un transbordador

44 Traducción del autor. 
espacial que transporta plutonio radiactivo. A mediados de la década siguiente, los ataques Dos se hicieron comunes, a menudo tomando la forma de mensajes o tráfico de información que superaba las capacidades; por ejemplo, en 1994, el grupo Zippies envió mensajes de correo electrónico en el Reino Unido para protestar contra un proyecto de ley que prohibía los festivales de música de baile al aire libre. El término hacktivismo fue acuñado en 1996 por el grupo de hackers Cult of the Dead Cow (culto de la vaca muerta), y el término adquirió ímpetu en los medios durante el conflicto de Kosovo de 1998-1999, cuando se lanzaron ataques de Dos contra sitios web en los países miembros de la OTAN. El hacktivismo se ha convertido en un medio común de protesta: existen grupos en todo el mundo, algunos se asocian con un país específico, como Siria anónima; otros se asocian con un Gobierno particular o un grupo político, como el califato cibernético, mientras que otros no expresan ninguna lealtad particular, tal como Anonymous ( $\mathrm{Si}$ mon, 2017, p. 2).

Anonymous, un grupo organizado de activistas hackers conocidos por usar las máscaras de Guy Fawkes, ganó popularidad con el lanzamiento del Proyecto Chanology, protestas lanzadas contra lo que el grupo identificó como censura en internet por la Iglesia de Cienciología. Desde entonces, el grupo ha sido responsable de ataques cibernéticos y hacktivismo contra gobiernos, organizaciones terroristas (que incluyen el Estado Islámico de Irak y Levante), corporaciones, grupos religiosos y presuntos delincuentes sexuales, entre otros. Los hacktivistas, además de los ataques Dos y los sitios web defectuosos, a menudo se apropian de las cuentas de Twitter y Facebook, hacen un uso extensivo de las redes sociales para promover sus acciones, robar y revelar información sensible de los sistemas que penetran. (Simon, 2017, p. 3)

Los hackers criminales (motivados por ganancias económicas a través de la penetración ilegal de redes informáticas y de naturaleza relativamente no violenta) operan en todo el mundo y han reemplazado las formas tradicionales de delincuencia. Se estima que han costado a la economía mundial un estimado de USD 445000 millones. En términos generales, el delito cibernético incluye el fraude, la venta en contrabando 
y los artículos falsificados y las estafas en línea. Luchar contra el cibercrimen es particularmente complicado, porque los crímenes a menudo impugnan los límites jurisdiccionales. Un hacker criminal puede sentarse en un país, usar un servidor alojado en otro y hackear sistemas alojados en un tercero, lo que hace que los componentes legales y geográficos del delito sean un desafío para investigar, y mucho más para procesar (Simon, 2017, p. 3).

El espionaje cibernético es una estrategia dirigida a la obtención de información crítica gubernamental o corporativa. China ha sido particularmente activa en la piratería estatal. Según un estudio, casi la mitad de todos los ataques de ciberespionaje en el mundo provienen de Asia oriental, en particular de China y Corea del Norte. Este último ha emprendido ataques de denegación de servicio contra Corea del Sur en la década reciente. También, Irán fue culpado en 2013 por atacar a Aramco, la compañía petrolera de Arabia Saudita, al borrar datos de aproximadamente 30000 computadoras y penetrar en las redes de la Royal Saudi Navy y Marine Corps (Simon, 2017, p. 3).

El 27 de agosto de 2011, un internauta iraní recibió una advertencia de un certificado inválido de su navegador cuando visitó el sitio web de Gmail. Informó este incidente a Google. El certificado fue generado el 10 de julio de 2011. Durante las semanas siguientes, se hizo evidente que el certificado fraudulento fue emitido por DigiNotar, un proveedor de certificados de seguridad holandés, después de una intrusión exitosa en sus servidores. El papel importante que DigiNotar cumple en los Países Bajos es triple. En primer lugar, DigiNotar es uno de los proveedores de certificados de seguridad para el Gobierno holandés. En segundo lugar, es un emisor de certificados para la Public Key Infrastructure (PKI) nacional holandesa (PKIoverheid). En tercer lugar, DigiNotar emite certificados para firmas calificadas. El marco para las firmas cualificadas es un intento por parte de la Unión Europea (UE) de otorgar un mayor valor jurídico a las firmas digitales. Poco a poco, quedó claro que los tres sistemas se habían visto comprometidos durante el robo. Esto implicaba que la confianza ya no podía situarse en la confidencialidad o integridad de los datos o comunicaciones que se habían obtenido con un certificado DigiNotar (National Cyber Security Center, 2014, p. 7). 
El viernes 25 de noviembre de 2011, se produjo un error de hardware en el proveedor de servicios de Tieto. Una parte central de un gran sistema de almacenamiento de datos en una instalación de Estocolmo sufrió un cierre de emergencia. En primer lugar, se perdió un importante componente del sistema. En ese momento, todavía habría sido posible recurrir a un sistema de respaldo que estaba en espera y listo para tomar el relevo. Sin embargo, después de un corto tiempo el sistema de respaldo también funcionó mal, lo que hizo que el almacenamiento de datos para los sistemas de servidor conectados no fuera funcional. La interrupción afectó a cerca de 50 clientes de Tieto, que incluyen empresas, agencias gubernamentales y municipios (National Cyber Security Center, 2014, p. 19).

El 16 de agosto de 2012, Symantec y Kaspersky Lab, seguidos de otros vendedores e investigadores, describieron un nuevo gusano de computadora modular, que fue denominado Shamoon. El malware fue parte de una serie de ataques de espionaje y sabotaje cibernéticos en Oriente Medio. Si bien no es notable por sus mecanismos de propagación, que explotan unidades compartidas y carpetas, lo es por su carga útil bastante única. Una vez que un sistema está infectado, Shamoon reúne archivos desde ubicaciones específicas del sistema, envía la información recolectada al atacante y reemplaza los archivos y los registros centrales del sistema con una imagen de una bandera americana en llamas. El grupo denominado Corte de Espada de Justicia reclamó la responsabilidad de usar Shamoon contra 30000 estaciones de trabajo de Saudi Aramco (empresa de petróleo estatal de Arabia Saudita), lo que ocasionó que la compañía pasara una semana restaurando sus servicios. Sorprendentemente, el ataque no afectó ninguno de las computadoras y redes de control de producción, y se limitó a los sistemas administrativos (Montanari y Querzoni, 2014, p. 37).

En septiembre de 2012, Deutsche Telekom AG, un ISP (internet service provider 'proveedor de servicios en internet'), fue atacado por adversarios desconocidos. El ataque de denegación de servicio fue un intento de bloquear el sistema de nombres de dominio del proveedor. Desde un punto de vista práctico, una interrupción del DNs (domain name system 'sistema de nombres de dominios') causaría una interrupción de internet para la mayoría de los clientes de ese proveedor. La 
telecomunicación e internet pertenecen a la infraestructura crítica de un país. Su interrupción podría tener efectos adversos significativos en el mismo. Para este ataque, el adversario utilizó la infraestructura de servidor de otro proveedor de alojamiento web (National Cyber Security Center, 2014, p. 15).

En diciembre de 2014, el Bundesamt für Sicherheit in der Informationstechnik (BSI) del Gobierno alemán publicó su informe anual de conclusiones. En un caso, notaron que un actor malicioso se había infiltrado en una instalación de acero. El adversario usó un correo electrónico de phishing para ganar acceso a la red corporativa y luego se trasladó a la red de la planta. Según el informe, el atacante mostró conocimiento en sistemas de control industrial y fue capaz de causar fallas en múltiples componentes del sistema. Esto afectó específicamente componentes críticos del proceso para no seguir las indicaciones programadas, lo que generó un daño físico masivo (Lee, Assante y Conway, 2014, p. 1).

En el transcurso de 2017, se presentó el software malicioso WannaCry, el cual afectó al NHs (National Health Service 'Servicio Nacional de Salud'), algunas de las compañías más grandes de España, que incluyen Telefónica, así como a computadoras en Rusia, Ucrania y Taiwán, lo que llevó a que la información fuera robada y guardada por los atacantes para luego pedir rescates económicos. Este ransomware utilizó una vulnerabilidad revelada por primera vez al público como parte de una filtración de documentos de la NSA para infectar las computadoras con sistema operativo Windows y cifrar sus contenidos, lo que les permitió exigir pagos de cientos de dólares con el fin entregar las claves para descifrar los archivos. El ataque coordinado logró infectar grandes cantidades de computadoras en todo el NHS en menos de seis horas después de que los investigadores de seguridad lo notaran por primera vez, debido a su capacidad de propagarse a través de las redes de computadora a computadora (Gibbs y Hern, 2017).

\section{El teatro robótico: llega la automatización}

Cuando los historiadores analicen las cuestiones de defensa en esta primera mitad del siglo xxi, observarán que los robots militares trajeron 
algo nuevo al mundo de la guerra y constituyeron un cambio aún más radical que la invención de las armas nucleares, ya que estos "no solo afectan a las modalidades de la guerra en constante cambio (cómo emprender la guerra), sino también a su esencia básica (quién hace la guerra)" 45 (Danet y Hanon, 2014, p. 13).

Un sector donde se ven claramente reflejadas las características positivas y facilidades que ha ofrecido la evolución tecnológica es por supuesto la robótica, principalmente en el ámbito militar, sin dejar de lado los demás, pero aclarando que casi siempre la seguridad y defensa son pioneros en avanzar en temáticas que faciliten sus procesos. Las armas no tripuladas mandan la parada en los conflictos de la actualidad para los ejércitos de países que pueden financiarlos, probarlos y usarlos: "Al contrario de las armas convencionales donde se arriesga uno o más soldados, los robots son manejados a kilómetros de distancia" ${ }^{46}$ (Leveringhaus y Giacca, 2014, p. 6).

En términos generales, un robot militar se define con más frecuencia como un "sistema que posee capacidades de percepción, comunicación, toma de decisiones y acción; es supervisado por combatientes humanos o actúa de manera autónoma de acuerdo con reglas preestablecidas de comportamiento y es capaz de mejorar su propio funcionamiento con aprendizaje automático" (Danet y Hanon, 2014, p. 17).

Entre las principales características que posee, o debería poseer un robot, se encuentra su movilidad, no poseer humanos en su interior, ser capaces de tomar ciertas decisiones por su cuenta (geolocalización, navegación, enrutamiento), ser un recurso que puede reemplazarse con facilidad, y estar aptos y capacitados para actuar según las instrucciones recibidas y el contexto en el que se encuentren (Lin, Bekey y Abney, 2008).

El nombre detrás de la idea de inteligencia artificial es John McCarthy, quien comenzó la investigación sobre el tema en 1955 y asumió que es posible describir cada aspecto del aprendizaje y otros dominios de inteligencia con tanta precisión que pueden ser simulados

45 Traducción del autor.

46 Traducción del autor. 
por una máquina. "La inteligencia artificial describe los procesos de trabajo de las máquinas que requerirían inteligencia si las realizaban los humanos" (Wisskirchen, Biacabe, Bormann, Muntz, Niehaus, Soler y Von Brauchitsch, 2017, p. 9). El término inteligencia artificial significa, por tanto, investigar el comportamiento inteligente de resolución de problemas y crear sistemas informáticos inteligentes.

Las tecnologías emergentes tienen distintos alcances en el desarrollo de la guerra. Pueden hacer más fácil, eficaz y con tasas de daños colaterales menores; estos sistemas pueden ser tremendamente costosos de construir y de implementar, y por supuesto, como todos los demás avances tecnológicos, crearán una relación dependiente aumentando los riesgos para la seguridad del actor que los implemente (Grauer, 2013).

La principal motivación detrás del desarrollo de armas autónomas tiene que ver con la distribución de la fuerza militar. La esperanza es que tales armas permitan a los comandantes desplegar su personal y su poder de fuego de una manera nueva e increíblemente efectiva. El DoD, por ejemplo, está desarrollando actualmente tecnologías para la tierra, el mar y el aire. En un escenario futuro, un pequeño número de pilotos supervisarían una gran flota de letales aviones autónomos. En otro escenario, los robots autónomos acompañarían a las tropas estadounidenses en la batalla. Estos robots podrían identificar la fuente de fuego hostil y tomar represalias inmediatamente, sin autorización humana:

Un argumento para las armas autónomas tiene que ver con la velocidad y la complejidad de la guerra moderna. La guerra es una carrera contra el tiempo. Quien sea capaz de pensar más rápido, tomar decisiones más rápido e iniciar operaciones militares inteligentes más rápido que sus enemigos, por lo general gana. Los militares tecnológicamente avanzados recurren cada vez más a las computadoras para compilar y analizar rápidamente cantidades masivas de información, que luego sirven de base para las decisiones estratégicas ${ }^{47}$. (Danish Institute For International Studies, 2017, p. 2)

47 Traducción del autor. 
Desde las dagas, espadas y lanzas a los arcos, la artillería y las armas de fuego en los aviones, los misiles de crucero y los misiles balísticos intercontinentales, las mejoras en el diseño de armas a lo largo del tiempo han permitido a los combatientes identificar y aniquilar a los otros a cada vez mayores distancias. La característica actual que ha facilitado y marcado un hito en la guerra moderna es la autonomía, pues no requiere la presencia en el campo de batalla, lo que aminora considerablemente los daños. La autonomía se define como la capacidad de sentir, decidir y actuar sin un comando humano. Es importante aclarar que aún ningún arma cuenta con autonomía total, pero sí con algún grado de ella como bombas inteligentes con GPS (global positioning system 'sistema de posicionamiento global') y mecanismos de control para actuar con precisión (Asaro, 2012).

Sin embargo, todavía los agentes humanos que controlan el sistema de armas deciden la selección de un objetivo y la determinación de su ubicación, el valor y los riesgos. Aún más autónomos son los sistemas que utilizan sensores de análisis sofisticados para seleccionar los objetivos apropiados por su cuenta y tomar decisiones sobre la idoneidad de las distintas acciones en respuesta a su situación. Las tecnologías emergentes de plataformas de armas robóticas incorporan algunas o todas estas características, el uso de procesamiento de imágenes para identificar objetivos y la selección de una amplia gama de acciones ofensivas y defensivas contra sus objetivos. Estas son las capacidades tecnológicas que ya existen y están comenzando a ser implementadas en varios paí$\operatorname{ses}^{48}$. (Asaro, 2012, p. 258)

Los robots, edificios inteligentes, automóviles que se conducen solos o aviones que vuelan de forma automática en un espacio aéreo controlado son ejemplos de sistemas ciberfísicos. Hoy, "los sistemas ciberfísicos pueden encontrarse en industrias tan diversas como la industria aeroespacial, automoción, energía, salud, manufactura, infraestructura,

48 Traducción del autor. 
electrónica de consumo y comunicaciones" ${ }^{49}$ (Steering Committee for Foundations for Innovation in Cyber-Physical Systems, 2012, p. 2).

El principal cambio es el aumento y la rápida proliferación de los sistemas no tripulados. Estos ya han reformado profundamente la estrategia de defensa y prioridades de adquisiciones estadounidenses y son cada vez más importantes en las Fuerzas Armadas de todo el mundo. Otras tecnologías emergentes que pueden perturbar el equilibrio militar mundial así son informática avanzada, inteligencia artificial, sensores densamente interconectados, armas eléctricas tales como energía dirigida, armas de riel electromagnético y armas de alto poder de microondas, fabricación de aditivos, la impresión 3D, biología sintética, entre otras (Work y Brimley, 2014). Todas estas tecnologías, impulsadas principalmente por la demanda y los avances en el sector comercial, están surgiendo hoy y tienen el potencial de provocar una nueva revolución técnico-militar.

La categorización de los robots no es muy precisa. No existe una tipología universalmente aceptada, y un análisis pone de manifiesto múltiples clasificaciones de diferentes tipos: clasificaciones técnicas (basadas en el tamaño de las plataformas robóticas) y clasificaciones funcionales o clasificaciones operativas (de acuerdo con las misiones o tareas de robots). Todas las caracterizaciones insisten en dos de las dimensiones fundamentales de la robotización del campo de batalla: "El grado de autonomía del robot y la perspectiva más o menos inminente de ver a los robots actuar en grupos. Por tanto, el robot debe ser considerado como una máquina autónoma o como un sistema de máquinas" ${ }^{50}$ (Danet y Hanon, 2014, p. 17).

Los conflictos requieren procesamiento de la información y respuestas mucho más rápidas, y frente a eso, los robots tienen una clara ventaja sobre las capacidades cognitivas limitadas y falibles de los humanos. No expandirían el espacio de batalla por alcanzar grandes áreas, también serían un multiplicador de fuerza, haciendo el trabajo de muchos soldados humanos, de modo que serían inmunes a la

49 Traducción del autor.

50 Traducción del autor. 
privación del sueño, fatiga, baja moral, perceptual y retos de la comunicación en la "niebla de guerra", y otras condiciones que obstaculizan el rendimiento (Lin, Bekey y Abney, 2008, p. 1).

El principal interés militar en los robots proviene del hecho de que ayudan a salvar vidas, en cualquier caso, es el credo de los fabricantes y uno de los factores impulsores en el uso de robots en las Fuerzas Armadas. Los robots son ante todo percibidos como herramientas que aumentan la eficiencia operativa de las fuerzas militares. Un robot no está sujeto a lapsos de concentración, ni a las mismas limitaciones fisiológicas que el cuerpo humano. No tiene hambre, no se asusta, ni se olvida de las órdenes. Y, por último, desde un punto de vista económico, el coste de un robot es menor que el de un soldado en funcionamiento. Un soldado estadounidense enviado a Afganistán equivale a un costo de USD 1 millón por año, incluido el entrenamiento. En comparación, un PackBot cuesta alrededor de USD 150 000, y un MARcbot, unos USD 5000 (Tisseron, 2014).

Vale la pena considerar las expectativas de los sistemas robóticos:

1. En primer lugar, los robots se utilizan para la protección, es decir, para reducir la exposición de un soldado a los riesgos. Asistencia en el desminado, ayuda en el reconocimiento de misiones, protección de convoyes en zonas de riesgo, limpieza de áreas CBRN (chemical, biological, radiological or nuclear 'químico, biológico, radiológico y nuclear'). Ellos crean una mayor distancia con las amenazas de combate, son los primeros en asumir el choque antes de la infantería y pueden detectar la ubicación exacta desde donde se hacen los disparos. Pueden responder en tiempo real en unos pocos milisegundos, como lo hacen los sistemas de mortero de artillería Counter Rocket, con un sistema integrado de toma de decisiones.

2. Los robots también están para aumentar la efectividad de un soldado que lucha, con lo que traen ventajas tácticas en la ejecución de su misión. Se utilizan sobre todo para extender las áreas de control y cobertura de una unidad táctica. Esto se hace mediante el uso de efectores remotos, sensores y armas colocadas a bordo de cada robot. En cierto sentido, son los 
"órganos remotos" de los ojos, los oídos, los brazos, el tacto e, incluso, la boca de un soldado.

3. Los robots pueden tener velocidades de despliegue mucho más altas que el hombre. Esto puede ayudar a anticipar las acciones del enemigo o a reaccionar inmediatamente a una amenaza con mayor eficiencia. Los robots también pueden ayudar en las maniobras mediante la identificación de las características del terreno para facilitar la progresión, la preparación del terreno o la seguridad de un área determinada.

4. Finalmente, los robots son una ayuda para reducir el uso de la energía humana: pueden reemplazar a los soldados en tareas repetitivas y tediosas (misiones de vigilancia y patrullas regulares, logística de transporte y suministros generales), y dejar espacio para que las fuerzas operativas actúen cuando sea necesario. Los robots también pueden ayudar llevando suministros, municiones e, incluso, armas durante misiones de larga distancia (nivel de la red de tierra). A un nivel más estratégico, los robots reducen el desgaste a medida que continúan las operaciones de combate, con lo que permiten a las unidades combatientes mantenerse en el campo de batalla mucho más tiempo que antes (De Boisboissel, 2014).

Esta tendencia no quita la importancia de la participación humana, pero sí cambia las funciones y los requisitos para los nuevos conjuntos de habilidades. Además, como los sistemas ciberfísicos son dependientes de los procesos computacionales, se vuelve cada vez más importante que estén diseñados para ser confiables y seguros. Los avances científicos y de ingeniería del futuro que amplían la conectividad de estos sistemas y ofrecen una mayor fiabilidad podrían abrir nuevas posibilidades para tomar ventaja de las propiedades únicas de sistemas ciberfísicos (Steering Committee for Foundations for Innovation in Cyber-Physical Systems, 2012, p. 3).

Como se ha dicho, los robots podrían llevar a cabo los trabajos más difíciles, arriesgados o arduos, de una forma tremendamente más eficiente. También podrían reducir drásticamente el comportamiento 
poco ético y los altos costos del desplazamiento de tropas y armamento a grandes distancias (Lin, Bekey y Abney, 2008).

Los militares pueden usar vehículos aéreos no tripulados (UAV 'unmanned aerial vehicle') para la vigilancia, pero también para bombardear blancos en el suelo. Hoy en día, muchos países producen y utilizan drones. Se han utilizado drones en Afganistán, Pakistán, Yemen y Somalia. Han matado tanto a combatientes como a civiles, no solo unos cuantos, sino cientos. Las principales razones por las que la tecnología es utilizada por los militares es que ayuda a lograr una táctica clave y un objetivo militar estratégico en tiempos de guerra: inflige tanto daño al enemigo mientras intenta arriesgar el menor número posible de personal y recursos ${ }^{51}$. (Coeckelbergh, 2013, p. 87)

La robótica autónoma tiene muchas aplicaciones en la partida militar, algunas de las cuales incluyen protección para los soldados que promueven condiciones de vida más seguras, mientras que otras están siendo diseñadas como sistemas de armas completamente operacionales. La robótica utilizada para la seguridad incluye la detección y destrucción de bombas. En la última década, los Estados Unidos han enviado más de 6000 dispositivos robóticos a Irak y Afganistán para ayudar a los soldados con la vigilancia y la gestión de las bombas. Los sistemas de armamento, sin embargo, aún están en desarrollo y llevarán años antes del despliegue, pero el consenso es que estas armas harían la guerra más segura poniendo menos soldados en peligro y limitando las bajas civiles (Clark, 2015).

La evolución de la robótica es sorprendente. George Devol fue quien creó brazos mecánicos en la década de 1960, pero no fue sino hasta 1980 que los modelos robóticos con cierto grado de autonomía llamaron la atención de algunos científicos. Los primeros robots creados por Grey Walter ya poseían características como sensores de luz y motores recargables (Lin, Bekey y Abney, 2008, p. 11).

51 Traducción del autor. 
Desde 2002, y tras la muerte en Yemen del terrorista Abu Ali al-Harithi, asesinado por un misil de un UAV Predator de la Agencia Central de Inteligencia (CIA 'Central Intelligence Agency'), el uso ofensivo de vehículos aéreos no tripulados se ha vuelto cada vez más frecuente para asesinatos selectivos. Los Estados Unidos dependían tanto de los UAV que, para el exdirector de la CIA, Leon Panetta (2009-2011), los UAV armados parecían ser la única arma eficiente para combatir a $\mathrm{Al}$ Qaeda en todo el mundo (Tisseron, 2014, p. 3).

Los avances más grandes en robótica se han hecho en vehículos aéreos no tripulados, con los Estados Unidos en la delantera, Israel detrás, y al menos otros 40 países tratando de ponerse al día. En el momento de la guerra de Irak en 2003, los Estados Unidos habían puesto en marcha seis grandes UAv: el Predator de la Fuerza Aérea, el Global Hawk, el Hunter, el Shadow, el Pioneer y el Dragon Eye. Estos variaban en tamaño, del Global Hawk de GBP 27000 (comparable a un jet de Lear) al Dragon Eye de GBP 5 (más bien como un aeroplano modelo). Lo que tenían en común era que estaban diseñados como sistemas de vigilancia. Pero en un patrón que hace eco de la historia del vuelo tripulado, los UAV como el Predator pronto se dispusieron a trabajar atacando posiciones enemigas (Boot, 2006, p. 23).

Los teatros de operaciones iraquíes y afganos han constituido vastos centros de experimentación al aire libre para los robots del mañana. El Big Dog, un robot cuadrúpedo capaz de acompañar a los soldados de infantería en terrenos accidentados y montañosos, para llevar equipo y otras cargas pesadas (hasta $150 \mathrm{~kg}$ ) a una velocidad de $4 \mathrm{~km} / \mathrm{h}$, es uno de esos robots que han sido enviados y probados en Afganistán. Otro ejemplo es el robot móvil swords (special weapons observation reconnaissance detection systems), armado con ametralladoras, desplegado en 2007 en Irak, que también fue desplegado en Afganistán. Su sucesor, el MAARS (modular advanced armed robotic system 'sistema robótico modular avanzado armado'), es de hecho una unidad más pesada. Puede ser equipado con una gama de armas diferentes: ametralladora, lanzagranadas, lanzacohetes, junto con altavoces para alentar al enemigo a rendirse o pedir a la población que abandone el área. También puede programarse para definir "zonas de disparo" y “zonas de exclusión” (Tisseron, 2014, p. 4). 
El uso de armas robóticas en el campo de batalla es otra manera de utilizar las Tic en la guerra. Se trata de un fenómeno cada vez más generalizado en el Ejército de los Estados Unidos, que desplegó 150 armas robóticas en la guerra de Irak en 2004 que culminó con 12000 robots para 2008. Hoy en día, varios ejércitos de todo el mundo están desarrollando y utilizando armas robóticas teleoperadas, que han sido desplegados en Irak y Afganistán, y las máquinas más sofisticadas están siendo utilizadas en las fronteras entre Israel y Palestina en la denominada "zona de muerte automática". Estos robots son capaces de detectar con precisión la presencia de enemigos potenciales, mediar la acción de los soldados humanos y disparar sobre blancos potenciales de enemigos cuando estos están dentro del rango patrullado por los robots. Varios ejércitos también invirtieron sus recursos para desplegar vehículos no tripulados, como los depredadores MQ-1, los cuales se han utilizado para golpear objetivos en tierra y desarrollar vehículos aéreos de combate no tripulados, que están diseñados para entregar las armas y potencialmente pueden actuar de forma autónoma, como el EADs Barracuda y el Northrop Grumman X-47B.5 (Taddeo, 2012, p. 109).

Israel está a la vanguardia en el campo de la robotización del campo de batalla, con trabajos que se basan directamente en los recientes combates. A su regreso de los 34 días de enfrentamientos violentos en el Líbano durante el verano de 2006, las unidades israelíes comprometidas informaron de sus dificultades para expulsar a los combatientes de Hizbulá afianzados en una red de refugios fortificados subterráneos construidos bajo la dirección de ingenieros iraníes y norcoreanos. Investigadores de la Universidad Ben Gurion, en colaboración con los del Israel Institute of Technology (Technion), desarrollaron un robot-serpiente de dos metros de longitud, capaz de arrastrarse por estrechos túneles. La cabeza de este robot está formada por sensores y cámaras que envían información a los soldados. También puede utilizarse para colocar una carga explosiva. En cuanto a la frontera con el Líbano y la franja de Gaza, para limitar los ataques a las tropas de patrulla, la vigilancia es proporcionada por un dispositivo controlado a distancia llamado el Guardium. Los robots son un recurso tecnológico que toma su lugar junto a las cercas o los muros de las fronteras cerradas (Tisseron, 2014, p. 4). 
Uno de los últimos tipos de arma robótica SGR-A1 se ha desplegado por Corea del Sur para patrullar la frontera con Corea del Norte. Este robot tiene una cámara de luz baja y un software de reconocimiento de patrones para distinguir a los humanos de los animales u otros objetos. También cuenta con una cámara en color, que puede localizar un objetivo a $500 \mathrm{~m} \mathrm{y}$, si es necesario, puede disparar su ametralladora incorporada. Hasta ahora, las armas robóticas fueron teleoperadas por militares sentados a millas de distancia de la zona de combate. En general, los hombres eran los que decidían si se debía disparar al objetivo y maniobrar el robot en el campo de batalla. El caso de SGR-A1 constituye toda una novedad, ya que tiene un modo automático, en el que se puede abrir fuego en el objetivo dado sin esperar a que el soldado humano valide la operación (Taddeo, 2012, p. 109).

El nuevo destructor $\mathrm{DD}(\mathrm{X})$ tendrá una sala de máquinas completamente controlada por sensores remotos y cámaras. O, para tomar otro ejemplo, considérese la evolución del bombardero de largo alcance desde el B-29, que tenía una tripulación de 11, hasta el B-2, que puede alcanzar muchos más objetivos, pero tiene una tripulación de solo dos, que pasan gran parte su tiempo supervisando las funciones del piloto automático (Boot, 2006, p. 23).

\section{El teatro cíborg: modificación del cuerpo humano}

Por otra parte, se ha llegado a interpretar la ciberguerra desde otro enfoque. El cuerpo humano está transformándose en una maquinaria de poder que lo explora, lo rompe y lo reorganiza. Una anatomía política, que es también una mecánica del poder, está naciendo, la cual define cómo se puede gobernar sobre los cuerpos de otros, no solo para que puedan hacer lo que se desea, sino para que puedan operar como se desea, con las técnicas, la velocidad y la eficiencia determinada (Masters, 2010). Una meta de larga data en la ingeniería es explotar los diseños únicos del cuerpo para guiar el desarrollo de apéndices artificiales antropomórficos que exhiben la estabilidad, la 
fuerza y la velocidad de tipo humano en una variedad de entornos naturales (Herr, Whiteley y Childress, 2003, p. 103).

Los científicos empezaron trabajando y pensando en dos grandes oleadas de investigación innovadora: el trabajo en computación y procesamiento electrónico de datos y el trabajo en cibernética, en la ciencia del control y en la comunicación en animales y máquinas. El camino por seguir sería combinar enfoques cibernéticos y computacionales para crear híbridos hombre-máquina, sistemas artefacto-organismo, en los que los dispositivos electrónicos implantados usaran señales corporales de retroalimentación para regular automáticamente la vigilia, el metabolismo, la respiración, la frecuencia cardiaca y otras funciones fisiológicas en maneras convenidas a un cierto ambiente extranjero (Clark, 2015, p. 13).

En el contexto contemporáneo, el cuerpo humano sigue siendo un lugar clave para el injerto tecnológico en el Ejército. Hoy en día, la moneda básica de la guerra, el cuerpo humano, es el sitio de estas modificaciones, ya sea del wetware (la mente y las hormonas), el software (hábitos, habilidades, disciplinas) o el hardware (el cuerpo físico). Sin embargo, estos argumentos no captan completamente la reconfiguración del soldado cíborg del siglo xxI. Algunas modificaciones son necesarias para seguir, complicar y contextualizar las reconfiguraciones contemporáneas de la subjetividad dentro del ejército (Masters, 2010).

Los seres biológicos y los sistemas informáticos comparten algunas bases físicas comunes. La comunicación tanto en sistemas nerviosos biológicos como en sistemas informáticos, por ejemplo, depende de las señales eléctricas. Sin embargo, la brecha entre estas dos clases de sistemas es obvia. Gracias a los nuevos desarrollos en tecnologías de neuroimagen, como la resonancia magnética funcional, la magnetoencefalografía y la tomografía por emisión de positrones, la brecha ya no es insuperable. Estas tecnologías permiten observar, en niveles crecientes de resolución y fidelidad, el funcionamiento interno del cerebro y revelar su estructura y función. Además, el progreso en las interfaces cerebro-máquina en la última década ha hecho posibles vías de comunicación directa entre el cerebro y los sistemas artificiales en la señal. Estos nuevos desarrollos representan avances significativos en la inteligencia 
cíborg. La inteligencia del cíborg intenta integrar estrecha y profundamente la inteligencia artificial con la inteligencia biológica, conectando los sistemas informáticos y sistemas biológicos, realzando fortalezas y compensando las debilidades de ambos al combinar las capacidades perceptivas y cognitivas de los sistemas biológicos con la energía computacional de los sistemas informáticos. En términos más generales, los cíborgs se refieren a sistemas simbióticos biológicos-mecánicos, compuestos por componentes tanto orgánicos como informáticos (Zeng y Wu, 2014, p. 3).

La palabra cíborg (del acrónimo en inglés cyborg: cyber, cibernético, y organism, organismo), es decir, organismo cibernético, se utiliza para designar una criatura compuesta por elementos orgánicos y dispositivos mecánicos para mejorar las capacidades biológicas a través de la tecnología. En otras palabras, es un individuo en parte hombre y en parte máquina (Mestres y Vives-Rego, 2016, p. 228).

El Oxford English Dictionary, por su parte, define el cíborg más explícitamente desde el punto de vista de aumento: como una persona cuyas tolerancias físicas o capacidades se extienden más allá de las limitaciones humanas normales por una máquina u otro dispositivo externo que modifica el funcionamiento del cuerpo, un sistema integrado hombre-máquina (Wittes y Chong, 2014, p. 9).

La cibernética ha dado el término cíborg, una unión de "organismo cibernético", que significa un organismo que es parte humano, parte máquina. Un cíborg es un individuo cuyas funciones biológicas son ayudadas o controladas por dispositivos tecnológicos, particularmente por implantes biónicos (Brey y Mitcham, 2005, p. 1529).

El término cíborg se ha definido como un ser humano cuyo funcionamiento fisiológico es mejorado por dispositivos mecánicos o electrónicos, una definición que parecía incluir individuos con cualquier número de implantes médicos en uso clínico común, tales como marcapasos cardiacos, pero el término usualmente se toma para involucrar mejoras más avanzadas, tales como prótesis neurales o implantes cerebrales (Doyle, 2014, p. 14).

En general, se usa el término tecnología cíborg para referirse a la tecnología integrada en el cuerpo humano que no solo restaura la función perdida, sino que realza las capacidades anatómicas, 
fisiológicas y de procesamiento de la información del cuerpo (Barfield y Williams, 2017).

Manfred Clynes y Nathan S. Kline en 1960 usaron el término en referencia a un humano mejorado que podría sobrevivir en entornos extraterrestres. Llegaron a esa idea después de pensar sobre la necesidad de una relación más íntima entre los humanos y las máquinas en un momento en que empezaba a trazarse la nueva frontera representada por la exploración del espacio. Los creadores del término cíborg pensaban en un proceso de autoconstrucción y mejora humana, y no en un proceso de creación de novo total y externo al propio hombre (Mestres y Vives-Rego, 2012, p. 229).

El acrónimo cíborg representa el organismo cibernético u organismo cibernéticamente controlado; se trata de un término destinado a captar tanto la noción de fusión de la máquina humana como la naturaleza más bien específica de la fusión prevista. Los cibernéticos estaban en especial interesados en los sistemas autorreguladores. "Estos son sistemas en los que los resultados de la propia actividad del sistema se retroalimentan para aumentar, detener, iniciar o reducir la actividad según lo dicten las condiciones" ${ }^{2}$ (Clark, 2003, p. 15).

Como máquina autorreguladora del hombre, el cíborg fue diseñado para proporcionar un sistema de organización en el cual los problemas, así como lo hacen los robots, sean solucionados de forma automática e inconsciente y dejen al hombre libre para explorar, crear, pensar y sentir. El cíborg es presentado como "la realización de una meta transhumanista concreta: el hombre liberado de las limitaciones estrictamente mecánicas de su organismo y las condiciones de su entorno por medio de la mecanización" 53 (Wittes y Chong, 2014, p. 6).

En los últimos años, se ha observado la aparición de la teoría del cíborg, o ciborgología, como el estudio multidisciplinario de los cíborgs y su representación en la cultura popular. Los estudios en la teoría del cíborg tienden a utilizar la noción del cíborg como metáfora

52 Traducción del autor.

53 Traducción del autor. 
para entender aspectos de la relación de la sociedad contemporánea con la tecnología, así como del cuerpo humano y del ser humano en general. En esta teoría, la noción de cíborg se refiere a los organismos híbridos, a los seres humanos contemporáneos con prótesis o implantes, así como a los seres humanos (contemporáneos) en general, que se piensa que son cíborgs en el sentido de ser inherentemente dependientes de la tecnología, como también se destaca en las teorías protésicas de la tecnología (Brey y Mitcham, 2005, p. 1531).

En primer lugar, consideramos que la vestimenta debe incorporarse como un primer criterio de "cyborización" bajo la consideración de que constituye un elemento de mejoramiento que desde hace miles de años ha permitido al hombre adaptarse a diversos ambientes. Son particularmente evidentes los casos de vestimenta técnica en el ejército o en el mundo del deporte, donde protege del clima, de los accidentes o de las acciones agresivas de humanos u otros animales. De hecho, los trajes protectores y el concepto de esqueleto externo o exosqueleto en los humanos actuales son una versión moderna de las armaduras clásicas que asumieron funciones de protección. Por otra parte, la idea de un esqueleto externo para acarrear cargas pesadas o para personas tetrapléjicas es relativamente reciente, y sus orígenes se remontan al "Hardiman" de 1966, construido por el ingeniero Ralph Mosher, que trabajaba para la empresa General Electric, aunque esa forma primitiva no fue exitosa, debido a su peso y a la brusquedad de sus movimientos. (Mestres y Vives-Rego, 2012, p. 230)

La definición del cíborg puede ser sostenida por una clasificación basada en el criterio de propósito o aplicación. En un grupo, están los cíborgs encargados de compensar cierta deficiencia física. Estos son predominantemente cíborgs médicos. En la vida real, abundan los seres humanos que se convirtieron en cíborgs por razones médicas. El segundo grupo consiste en seres humanos que han incorporado las partes mecánicas para realzar su potencial corporal. Estos son llamados cíborgs experimentales. Las desventajas físicas no los han obligado a aceptar elementos inorgánicos dentro de su organismo. Ellos han optado por hacerlo con fines de experimento científico o en forma de 
presentaciones artísticas, pero principalmente para ilustrar las implicaciones éticas o políticas de este acto (Glavanakova, 2006).

Las capacidades de la "tecnología cíborg" tienen varias características: 1) la tecnología es actualizable, lo que permite que las mejoras de software y hardware sean aplicables al cuerpo en ciclos de tiempo cada vez más cortos; 2) la tecnología ofrece al cuerpo capacidades computacionales adicionales, con lo que lo transforma en una tecnología de procesamiento de información; 3) la tecnología cíborg se integra con el cuerpo mediante sistemas de realimentación, y 4) es cada vez más controlable por el pensamiento. Si estas tendencias de la innovación y la investigación continúan, pronto será posible encontrar un tipo nuevo de humano con capacidades muy diferentes (Barfield y Williams, 2017).

La fusión de lo humano con lo tecnológico, que ahora es un hecho social que cobra cada vez más ímpetu, forma parte de visiones distópicas del futuro lejano y no tan lejano, así como una resistencia a la dominación de la información. Esta tecnoansiedad, asociada al mal uso de las máquinas con fines de coerción, dominación y vigilancia de los seres humanos, resurge como tema central en el debate sobre el destino de la ciudadanía. El grado de control sobre los seres humanos mediante el empleo de tecnologías digitales es más notable en dos figuras: los militares y los cíborgs de vigilancia. La guerra posmoderna está fuertemente influenciada por la tecnociencia y depende de los cíborgs. Ahora los militares estadounidenses producen continuamente soldados más fuertes y más eficientes mediante el uso de instrumentos mecánicos y digitales (Glavanakova, 2006).

Recientes áreas de investigación de inteligencia cíborg han incluido los siguientes temas:

- Animales como sensores y actores.

- Máquinas controladas por la mente.

- Neurochips, chips diseñados para conectarse a células neuronales; por ejemplo, chips de memoria para reemplazar la corteza de memoria para su restauración y mejora. 
- Prótesis inteligentes, dispositivos que reemplazan una parte del cuerpo perdida o dañada usando el sistema nervioso humano y la interfaz del cerebro para aumentar la precisión y lograr la comodidad de los movimientos.

- Neuromorfos, sistemas de software análogos, digitales y mixtos que implementan modelos de sistemas neuronales (como la percepción, el control motor y la integración multisensorial).

- Cognición simbiótica, integración de funciones cognitivas biológicas con modelos computacionales de cognición (Zeng y Wu, 2014, p. 3).

Las tecnologías cíborg se pueden dividir en cinco categorías: tecnologías que interfieren externamente con el cuerpo, implantes dentro del cuerpo, tecnología que modifica las actividades cerebrales, tecnología informática que mejora la calidad de vida y exoesqueletos (Barfield y Williams, 2017).

Las mejoras externas generales al organismo incluyen las prótesis para reemplazar o restaurar funciones perdidas, las cuales son cada vez más controlables mediante el uso de principios de la teoría de control, y están integralmente conectadas al cuerpo, son actualizables y, bajo ciertas circunstancias, controladas por el pensamiento a través de una interfaz cerebro-computadora. Y por otro lado, se encuentran los accesorios de computación como mejora, ya que, al incrementar los recursos computacionales a través de la tecnología directamente integrada con el cuerpo, permiten escalar capacidades, sentidos e interacción con el entorno y con tecnología externa. En la medida en que la computación portátil se integra con los sentidos y responde a los pensamientos, representa un movimiento significativo hacia convertirse en un cíborg (Barfield y Williams, 2017).

En segundo lugar, se encuentran las tecnologías de mejora implantada dentro del cuerpo de tres tipos. El implante pasivo cíborg, si bien no puede interactuar con el cuerpo a través de un bucle de retroalimentación, puede ser llevado en el cuerpo, o recolectando o almacenando información. Los implantes activos o sensores sí cuentan con realimentación en circuito cerrado, junto con capacidades computacionales que proporcionan información médica, interacción tecnológica y 
entrada extrasensorial. Y la interfaz con el sistema nervioso está completamente integrada con el cuerpo y proporciona mayores niveles de integración con el usuario. A través de dicha integración, los circuitos de retroalimentación que sus sistemas crean pueden considerarse extensiones artificiales del cuerpo (Barfield y Williams, 2017).

Como tercera categoría, se encuentran las mejoras o modificaciones del cerebro. En el neurocontrol, se hace referencia a interfaces con menor especificidad, en general usadas para suprimir grandes grupos neuronales afectados por alguna enfermedad. En la lectura de la mente, la actividad de la neurona se mide por primera vez, luego se traduce por una computadora y finalmente se envía como una forma de salida. Por último, las tecnologías que influyen en la memoria pueden crear y desmantelar la identidad, así como curar enfermedades degenerativas, ayudar en el aprendizaje y ampliar las bases de conocimiento (Barfield y Williams, 2017).

Las últimas clases incluyen exoesqueletos y ayudas a la movilidad. Las prótesis de función aumentada, si bien no están técnicamente separadas en la clasificación cíborg de las prótesis normales, tienden a ser menos antropomórficas, tienen funciones de control del pensamiento y especificaciones de diseño destinadas a mejorar ciertas habilidades, y los exoesqueletos están diseñados alrededor de las extremidades existentes para aumentar la movilidad. Estas mejoras pueden aumentar considerablemente las capacidades naturales o restaurar la funcionalidad perdida. Todos son sistemas de retroalimentación de circuito cerrado con el cuerpo y, además, los exoesqueletos poderosos contienen sistemas computacionales que aumentan su nivel de mejora (Barfield y Williams, 2017).

El soldado de tierra cíborg del siglo xxI estará equipado con tecnologías que en esencia reemplazan sus sentidos a través de prótesis tecnológicas que replican los sentidos biológicos mientras evitan las limitaciones biológicas humanas: visión, oído y discernimiento deficiente. Su casco estará equipado con micrófonos y auriculares para la comunicación, gafas de visión nocturna y sensores de imagen térmica para ver en la oscuridad, junto con una pantalla de avisos delante de sus ojos para mostrarle dónde está en el suelo y darle constantes actualizaciones sobre inteligencia. 
La DARPa (Defense Advanced Research Projects Agency 'Agencia de Proyectos de Investigación Avanzados de Defensa') también está desarrollando tecnología que puede regular las emociones al enlazar directamente al sentido y controlar remotamente el desempeño de un soldado; se podrían eliminar sentimientos de miedo, vergüenza o agotamiento. Lo que una vez se consiguió al enviar soldados con anfetaminas ahora se puede hacer a distancia con mayor precisión. Con tales desarrollos, los “ojos” y “oídos” de los militares ya no serían susceptibles al error humano y a la emoción, porque las computadoras no están a merced de las funciones corporales, incluso mientras no funcionan sin la presencia de los seres humanos. Los programadores informáticos que manejan computadoras siempre pueden ser reemplazados con relativa facilidad y sin interrumpir sus capacidades. Además, la computadora recomienda los objetivos que deben ser atacados e, incluso, vigila los cielos desde lejos (Masters, 2010).

El cibersoldado 2030 propone elementos ergogénicos y monitorización que pueden ser proporcionados por la corriente del cíborg y harán al combatiente mucho más eficiente, como lo son:

- El exoesqueleto integrado basado en la nanotecnología: velocidad, fuerza y agilidad mejoradas.

- Potenciadores cognitivos (nutricionales, nootrópicos u otros fármacos inteligentes).

- Mejoradores físicos (nutricionales, farmacéuticos).

- Prótesis neurales (ahora controvertidas, pero quizá omnipresentes en 2030).

- Comportamiento neural.

- Análisis interno (detección de oxigenación sanguínea y glucosa).

- Un modelo predictivo individual del desempeño en función de variables de estado (Casey, 2009, p. 4).

El cíborg se puede leer fundamentalmente como poshumano y representa significativamente una profunda rearticulación de lo político; en 
otras palabras, la constitución del soldado cíborg se puede leer como una rearticulación radical de la subjetividad humana. Esta subjetividad poshumana está representada a través del cíborg en los procesos mismos de transferir el razonamiento humano y el pensamiento de sujetos humanos a la tecnología (Masters, 2010). La fusión de la tecnología con la capacidad de razonar y pensar, sin ser interrumpido por emociones como la culpa o las limitaciones corporales como la fatiga, es indicativo de la constitución del cuerpo carnoso como incapaz de producir y proyectar los requerimientos deseados.

En la neurociencia, ha habido experimentos espectaculares en los últimos años que están rompiendo los esquemas de los cíborgs en la ciencia ficción. Por ejemplo, los sistemas BCI (brain-computer interface 'interconexión cerebro-ordenador') se empezaron a experimentar en la Universidad de California en la década de 1970. Estos consisten en una comunicación por cableado entre el cerebro y una computadora externa que permite la interacción biyectiva. Con esta conexión, se podría modificar las imágenes-datos que se ven en la computadora, y viceversa, a partir de instrucciones a esta para poder cambiar funciones motoras, sensitivas y emocionales (Mestres y Vives-Rego, 2012, p. 232).

Kevin Warwick puede ser la persona más conocida al unir estos dos mundos. El 24 de agosto de 1998 fue objeto del experimento Cyborg 1.0, donde se le implantó debajo de la piel un chip RFID (radio frequency identification) con el cual fue capaz de controlar puertas, luces, calentadores y computadoras solo con la señal emitida por el chip. Un segundo experimento fue el Cyborg 2.0, realizado el 14 de marzo de 2002. Un chip de mayor complejidad fue implantado en el sistema nervioso de Warwick por medio del cual fue capaz de mover una mano cibernética utilizando la interfaz neuronal. Además, se le implantó también a su esposa un microchip, con el objetivo de crear alguna clase de telepatía o empatía, lo que permitió la primera comunicación puramente electrónica entre dos sistemas nerviosos humanos (Mestres y VivesRego, 2012, p. 233).

El estadounidense Michael Chorost, nacido en 1964, tenía graves pérdidas auditivas debido a la rubeola. Su audición fue parcialmente restaurada con un implante coclear y se "convirtió" en un cíborg el 1 de octubre de 2001. Posteriormente, escribió una memoria de la 
experiencia titulada Rebuilt: How Becoming Part Computer Made Me More Human ('Reconstruido: Cómo convertirme en parte computadora me hizo más humano'). Allí describe cómo su cuerpo se volvió desconcertantemente mecánico, pues su audición está rutinariamente actualizada con un nuevo software (Glavanakova, 2006).

Un reciente ejemplo de un cíborg militar es un anuncio publicado en los sitios web del Gobierno estadounidense por la DARPA, en el que se afirma que está en busca de propuestas innovadoras a fin de desarrollar tecnología para crear cíborgs de insectos, mediante la implantación de pequeños dispositivos en sus cuerpos. El objetivo era crear tecnología que pudiera lograr la llegada de un insecto a menos de $5 \mathrm{~m}$ de un objetivo específico utilizando control remoto electrónico o GPS (global positioning system 'sistema de posicionamiento global'). Agregado a esto, el insecto debía permanecer inmóvil indefinidamente o hasta que se instruyera de otra manera y también debía ser capaz de transmitir datos de los sensores pertinentes del DoD que incluyen sensores de gas, micrófonos, video, etc. (Glavanakova, 2006).

Ejemplos de prótesis pueden ser DEKA Arm, un brazo controlado por el cerebro, un telescopio implantado en miniatura para el tratamiento de la DMAE (degeneración macular asociada a la edad), el Argus II Retinal Prosthesis System, un dispositivo implantado para tratar a adultos con retinitis pigmentosa grave y el MED-EL's Synchrony, implante coclear. Entre los accesorios tecnológicos, ahora es posible encontrarse USB (universal serial bus 'conexión de serie universal') como reemplazos de prótesis de dedos (USB Fingertip), una cámara que se lleva delante del ojo para grabar la escena disponible a la vista junto con una pantalla para superponer imágenes generadas por computadora en la escena original disponible (EyeTap); las Google Glass, un aparato diseñado para percibir los colores mediante ondas sonoras en tiempo real (eyeborg); y un monitor sobre la piel, capaz de dar al hombre una sensación constante de ubicación (Barfield y Williams, 2017).

En cuanto a tecnologías implantadas, se encuentran los chips RFID (radio frequency identification 'identificación por radiofrecuencia'), una tecnología inalámbrica capaz de identificar automáticamente, transferir datos de una etiqueta electrónica a través de un lector con 
el propósito de rastrear a la persona y guardar su información vital (Ajami y Rajabzadeh, 2013, p. 809).

También se incluyen monitores de marcapasos y desfibriladores cardiacos para una función cardiaca correcta, estimuladores de nervios que interactúan entre el sistema inmunológico y el nervioso para tratar una amplia gama de enfermedades relacionadas con la inflamación, desde la diabetes hasta la insuficiencia cardiaca congestiva. Los sensores implantables miden y transmiten los niveles de glucosa; el Circadia de Tim Cannon mide la temperatura; el sensor sísmico de Moon Ribas vibra para predecir los terremotos; la implantación de micrófonos y altavoces en los dientes; un controlador inalámbrico activado por el cerebro; la investigación de Kevin Warwick le permitió controlar un brazo robot y crear una sensación nerviosa artificial, entre otras (Barfield y Williams, 2017).

Respecto de temas de manejo e influencia en el cerebro, ya hay avances importantes. Theodore Berger, ingeniero biomédico y neurocientífico de la Universidad del Sur de California en Los Ángeles, ha diseñado chips de silicio para imitar el procesamiento de las señales que hacen las neuronas interrumpidas tras haber sufridos daños por alzhéimer, accidentes cerebrovasculares o lesiones, cuando funcionan correctamente, que permiten recordar experiencias y conocimientos (Cohen, 2013).

La DARPA ha reconocido la TBI (traumatic brain injury 'lesión cerebral traumática') como una causa grave de discapacidad en los Estados Unidos. Se ha diagnosticado a más de 270000 miembros del servicio militar desde 2000 y ha afectado a un estimado de 1.7 millones de civiles estadounidenses cada año. La тв frecuentemente resulta en una capacidad deteriorada para recuperar recuerdos formados antes de la lesión y una capacidad reducida para formar o retener nuevos recuerdos después de ella. Actualmente, existen pocas terapias eficaces para mitigar las consecuencias a largo plazo en la memoria. A través de la RAM (Restoring Active Memory), la DARPA busca acelerar el desarrollo de una tecnología capaz de abordar este desafío de salud pública y ayudar a los miembros de los servicios y otros a superar los déficits de memoria mediante el desarrollo de nuevas neuroprótesis para cerrar las brechas en el cerebro lesionado. El objetivo final de la 
RAM es desarrollar y probar un dispositivo médico de interfaz neuronal totalmente implantable para el uso clínico humano. La DARPA apoya el desarrollo de modelos computacionales de múltiples escalas con alta resolución espacial y temporal que describen cómo las neuronas codifican los recuerdos declarativos. Los investigadores también explorarán nuevos métodos para el análisis y la decodificación de señales neurales a fin de entender cómo la estimulación dirigida podría ser aplicada para ayudar al cerebro a restablecer una capacidad para codificar nuevos recuerdos después de una lesión cerebral (Sánchez, 2017).

El desarrollo cíborg ha llegado hasta el punto del manejo de algunos aspectos cerebrales. Los neurocientíficos del Massachusetts Institute of Technology (MIT) han demostrado que pueden plantar falsos recuerdos en el cerebro de los ratones y encontraron que muchos de los rastros neurológicos de estos recuerdos son idénticos en naturaleza a los de memorias auténticas. El estudio también proporciona pruebas adicionales de que los recuerdos se almacenan en redes de neuronas que forman rastros de memoria para cada experiencia y muestra que se podía identificar las células que forman parte de un engrama (recuerdos) para una memoria específica y reactivarla usando una tecnología llamada optogenética (Trafton, 2013).

Biomechatronics de Hugh Herr ha desarrollado prótesis de rodilla adaptativas para amputados transfemorales y órtesis de tobillo-pie de impedancia variable para pacientes que sufren la pérdida de sus pies, patología de la marcha causada por accidente cerebrovascular, parálisis cerebral y esclerosis múltiple. También ha diseñado sus propias extremidades biónicas, como la primera pierna biónica del mundo, llamada віом ${ }^{\circledR}$ Ankle Foot System. Esta ha demostrado clínicamente ser la primera prótesis de pierna que logró la normalización biomecánica y fisiológica y permitió a las personas con amputación de piernas caminar con los niveles normales de velocidad y metabolismo como si las piernas fueran biológicas de nuevo (MIT Media Lab People, s. f.).

California suitX está encaminado en conquistar la industria del exoesqueleto. No solo la compañía ha desarrollado su exoesqueleto Phoenix, que es el menos caro y más ligero entre los exoesqueletos médicos disponibles, sino que suitX también ganó el premio de USD 1 millón 
en AI \& Robotics for Good de los Emiratos Árabes Unidos con su propuesta para un exoesqueleto médico pediátrico, y superó a otras 659 entradas en la categoría internacional del evento. suitX fue fundada por Homayoon Kazerooni, quien tiene más de treinta años de experiencia en ingeniería mecánica y un doctorado del MIT. De hecho, Kazerooni, incluso, fue cofundador de Ekso Bionics (Talking Exoskeletons with suitX Founder Dr. Homayoon Kazerooni, 2016).

Los cuatro teatros donde se desarrolla la ciberguerra, todos ellos expuestos para facilitar su comprensión, son una clara muestra sobre varias cosas: en primer lugar, que la ciberguerra y el ciberespacio ya han permeado todos los sectores de la vida política, económica, militar, social y cultural a nivel internacional; pues, si bien hay lugares con mayor penetración que otros, una gran parte de los procesos humanos ahora dependen de las conexiones a internet, que, si bien han facilitado la vida de muchos individuos, también han abierto caminos para aprovechar las vulnerabilidades que se crean.

Y en segundo lugar, los tipos de ciberguerra demuestran que esta no es una sola a la que el ciberespacio le otorga la cualidad de transformarse y adaptarse a la necesidad del atacante y a las debilidades del adversario, que, si se tiene el dinero, la voluntad de los dirigentes o líderes y la información, la ciberguerra se convierte en una oportunidad de un gran valor para cualquiera que tenga un interés, una herramienta y conocimientos cibernéticos y ciberespaciales. 